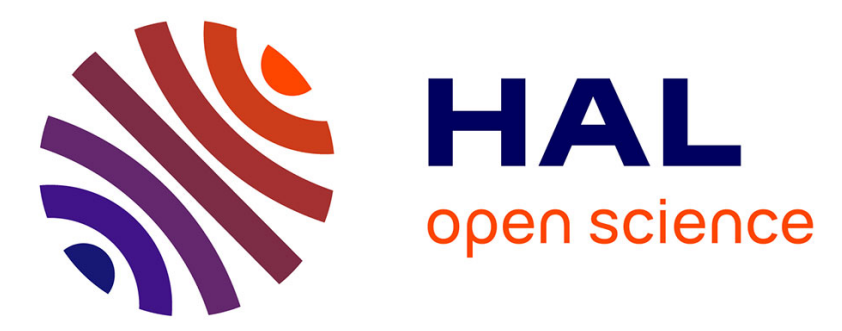

\title{
An energy-equivalent bridging map formulation for modelling delamination in through-thickness reinforced composite laminates
}

\author{
António R Melro, Joël Serra, Giuliano Allegri, Stephen R Hallett
}

\section{- To cite this version:}

António R Melro, Joël Serra, Giuliano Allegri, Stephen R Hallett. An energy-equivalent bridging map formulation for modelling delamination in through-thickness reinforced composite laminates. International Journal of Solids and Structures, 2020, 202, pp.153 - 165. 10.1016/j.ijsolstr.2020.06.018 . hal-03325885

\section{HAL Id: hal-03325885 \\ https://hal.science/hal-03325885}

Submitted on 25 Aug 2021

HAL is a multi-disciplinary open access archive for the deposit and dissemination of scientific research documents, whether they are published or not. The documents may come from teaching and research institutions in France or abroad, or from public or private research centers.
L'archive ouverte pluridisciplinaire HAL, est destinée au dépôt et à la diffusion de documents scientifiques de niveau recherche, publiés ou non, émanant des établissements d'enseignement et de recherche français ou étrangers, des laboratoires publics ou privés. 
See discussions, stats, and author profiles for this publication at: https://www.researchgate.net/publication/342349833

\section{An energy-equivalent bridging map formulation for modelling delamination in through-thickness reinforced composite laminates}

Preprint in International Journal of Solids and Structures · June 2020

DOI: 10.1016/j.jijsolstr.2020.06.018

\section{CITATIONS}

2

4 authors:

António R. Melro

U. University of Bristol

32 PUBLICATIONS 1,021 CITATIONS

SEE PROFILE

Giuliano Allegri

University of Bristol

111 PUBLICATIONS 1,219 CITATIONS

SEE PROFILE

Some of the authors of this publication are also working on these related projects:

Project VERTEX Project View project

Project Extending the range of applications for Z-pins in composites View project
Bef Joel Serra

Institut Supérieur de l'Aéronautique et de l'Espace (ISAE)

9 PUBLICATIONS 46 CITATIONS

SEE PROFILE

Stephen R. Hallett

University of Bristol

262 PUBLICATIONS 6,748 CITATIONS

SEE PROFILE 


\section{Journal Pre-proofs}

An energy-equivalent bridging map formulation for modelling delamination in through-thickness reinforced composite laminates

António R. Melro, Joël Serra, Giuliano Allegri, Stephen R. Hallett

PII: S0020-7683(20)30240-7

DOI: https://doi.org/10.1016/j.ijsolstr.2020.06.018

Reference: SAS 10756

To appear in: International Journal of Solids and Structures

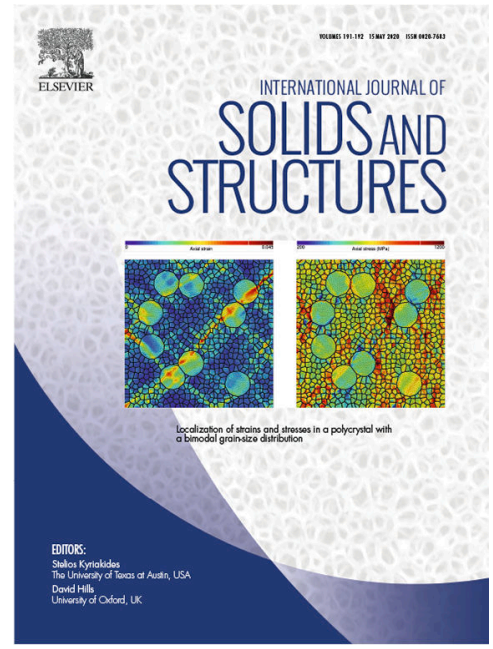

Received Date: $\quad 1$ August 2019

Revised Date: $\quad 30$ April 2020

Accepted Date: $\quad 12$ June 2020

Please cite this article as: A.R. Melro, J. Serra, G. Allegri, S.R. Hallett, An energy-equivalent bridging map formulation for modelling delamination in through-thickness reinforced composite laminates, International Journal of Solids and Structures (2020), doi: https://doi.org/10.1016/j.ijsolstr.2020.06.018

This is a PDF file of an article that has undergone enhancements after acceptance, such as the addition of a cover page and metadata, and formatting for readability, but it is not yet the definitive version of record. This version will undergo additional copyediting, typesetting and review before it is published in its final form, but we are providing this version to give early visibility of the article. Please note that, during the production process, errors may be discovered which could affect the content, and all legal disclaimers that apply to the journal pertain.

(C) 2020 Published by Elsevier Ltd. 


\title{
An energy-equivalent bridging map formulation for modelling delamination in through-thickness reinforced composite laminates
}

António R. Melro ${ }^{a, 1}$, Joël Serraa, Giuliano Allegria, Stephen R. Hallett ${ }^{a}$

aBristol Composites Institute (ACCIS), University of Bristol, Queen's Building, BS8 1TR, UK

\begin{abstract}
A new multi-scale framework to numerically model the bridging effect in throughthickness reinforced (TTR) composite laminates with z-pins is presented. The framework first establishes a library of bridging maps, calculated by a micromechanical semi-analytical constitutive bridging model. For the macro-scale, a tri-linear cohesive law has been developed to model initiation and propagation of the interfacial damage in the presence of z-pins. The cohesive law takes into account the energy dissipated by delamination propagation through the matrix in the interlaminar region, plus the energy contributed by the z-pin bridging up to complete pull-out from the laminate or z-pin failure. The information regarding the failure mode and the consequent dissipated energy comes from the library of bridging maps. The trilinear cohesive law has been implemented in a user material subroutine of a commercial finite element software. The framework has been validated against experimental data and an excellent correlation has been achieved.
\end{abstract}

Keywords: Through-thickness reinforcement (TTR), damage tolerance, cohesive models, delamination, finite element analysis

\footnotetext{
${ }^{1}$ Corresponding author

Email address: antonio.melro@bristol.ac.uk (António R. Melro)
} 


\section{Introduction}

Laminated carbon fibre reinforced polymers (CFRPs) have low interlaminar resistance and are therefore vulnerable to delamination between plies (1). Delamination damage causes significant reduction in the stiffness of a composite structure, which may lead to premature catastrophic failure. Through-thickness reinforcement (TTR) technologies for composite materials have been shown to improve the resistance of a structure to delaminations (2). One of these techniques, known as z-pinning, involves the insertion of small diameter fibrous or metallic pins through the thickness of a laminated composite material (3). This reinforcement process is performed prior to final cure and results in a composite structure with a significantly increased delamination resistance.

Throughout the years, the mechanisms of crack bridging have been investigated both for a variety of z-pin materials (pultruded carbon-fibre composite, glass-fibre composite, metals) (4-7) and shapes (angled, threaded) (8), a variety of loadings (static, fatigue, dynamic) (9-11) and structural configurations (impacted specimens, junctions) $(12,13)$.

Several approaches have been proposed to capture the bridging behaviour of z-pinned composite laminates. Two length scales are typically required on such approaches: the micro-scale where the individual z-pin behaviour is modelled and the macro-scale where the combined behaviour of arrays of z-pins needs to be considered. Analytical $(14,15)$ and highfidelity numerical models (16-19) of the z-pin embedded in a composite laminate make it possible to predict the bridging effect of an individual z-pin. This prediction can then be used as input data for large macro-scale models of structural components.

At the macro-scale, two main modelling strategies have been pursued in recent years. The first strategy uses discrete spring elements to simulate the behaviour of individual z-pins 
$(12,20)$. The disadvantage of this method is the need to know the exact location of each z-pin in the laminate and to include the discrete spring elements in the model at those specific locations. This constraint complicates the pre-processing of the FE model, as structural components may contain thousands of z-pins. Blacklock et al. (21) proposes using a truss element embedded within the laminate, providing a reduction in computational cost, but this approach would require very fine meshes at structural level.

The second strategy applies a smearing approach to a standard cohesive interface (2225). The properties of the cohesive elements need to be calibrated in advance, most of the times even for different mode-mixity values, leading to numerical models which are valid only at specific loading conditions. An extended approach to different mode-mixity values was presented by Cui et al. (25), based on smearing the bridging effect of z-pins across two distinct layers of cohesive elements along the interface. However, this still required to consider the individual z-pin positions. Each layer of cohesive elements would give either the bridging normal traction or shear force. The cohesive properties need to be determined in advance through multiple experimental tests at different mode-mixities. The main disadvantage of this implementation is the need to superpose cohesive elements in the model and assign different properties to them, in the specific locations occupied by individual z-pins.

Mohamed et al. (26) proposed a multi-scale framework, combining a smeared bridging effect along the interface of cohesive elements with a semi-analytical constitutive bridging model from Allegri et al. (15). The analytical model can estimate the exact bridging map for an individual z-pin in the form of a pair of three-dimensional (3D) surfaces, which relate traction and shear forces with opening and sliding displacements. A library of bridging maps could thus be generated, and any structural model could be fed with this information. 
However, the search on 3D surfaces for the correct traction and shear forces as a function of current mode-mixity at every time increment on an explicit FE model is computationally expensive. This approach would also fail to meet the correct stiffness provided by the bridging z-pins to the interface, leading to a very compliant general behaviour unless the exact locations of the z-pins on the interface were accounted for and explicitly modelled.

In this paper, a new smeared approach to simulate the bridging action exerted by z-pins under any mode-mixity regime is presented. Predictions from a micro-mechanical constitutive bridging model are integrated into the cohesive element formulation. A special user-defined cohesive element formulation is developed, which can capture the interfacial behaviour of both resin-rich unpinned interlaminar regions, as well as the large-scale bridging mechanism due to the presence of z-pins. At each time increment, the mixed-mode displacement at the integration point is used to identify the amount of energy being dissipated by the z-pin and the predicted total displacement at failure for that specific modemixity. This information is used to reverse-build a tri-linear cohesive constitutive law, which accounts for both the amount of energy dissipated by the bridging action and the total displacement at failure of the z-pin. This process allows to calculate the traction and shear components of the bridging forces acting along the cohesive interface. The procedure has been named the Energy-Equivalent Bridging Map (EEBM) formulation. This multi-scale framework has then been validated against a comprehensive set of experimental data for different loading conditions and mixed-mode ratios.

\section{Framework}

A multi-scale modelling framework has been developed to capture the bridging effect introduced by through-thickness reinforcements such as z-pinning (Figure 1). 


\section{Meso-scale experimental characterisation}

Single z-pin characterisation tests are performed to measure the individual bridging effect of a z-pin as a function of mode-mixity $(\phi)$.
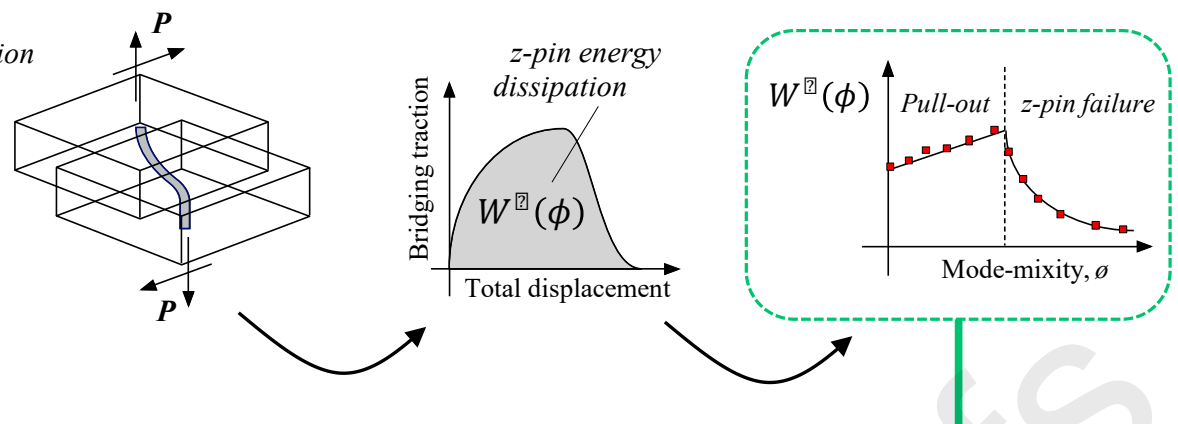

\section{Model calibration and validation}

\section{Micro-mechanical bridging model}

Z-pin analytical description:

Euler-Bernoulli

beams embedded in

an elastic foundation.

\section{Mixed-mode (I-II) response}

Equilibrium equations relate opening $(W) /$ sliding $(U)$ displacements to bridging

forces exerted by the z-pin.

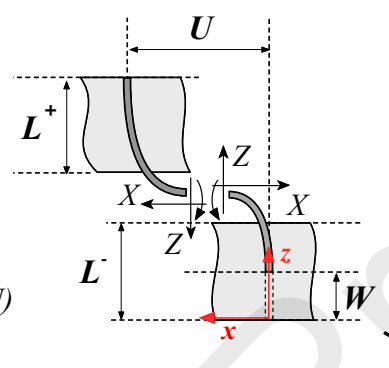

For each mode-mixity the amount of dissipated energy is calculated, as well as displacement at z-pin pull-out or bending failure.

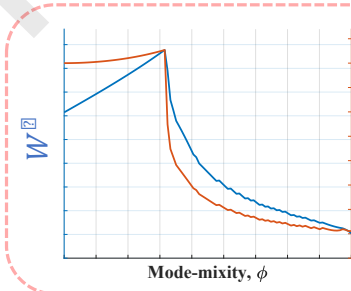

\section{Energy-equivalent bridging map}

\section{Macro-scale FE analysis}

A tri-linear cohesive law is defined from the micro-mechanical bridging model.
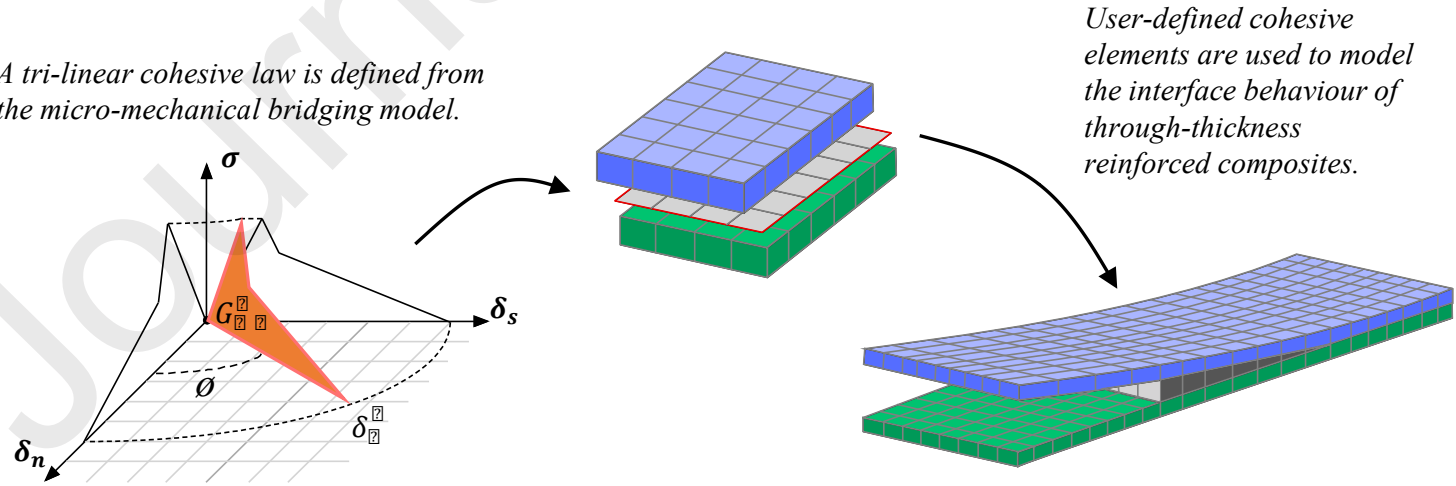

Figure 1. Multi-scale framework for modelling of through-thickness reinforced composites. 
A series of experimental characterisation tests of the bridging effect of a single z-pin were performed at different mode-mixities. The z-pin is orthogonally inserted in a specific fibre bed - polymer matrix composite. Further details can be found in (26). The output of these measurements are the bridging tractions versus total displacements, which allow to calculate the apparent enhancement to the fracture toughness brought by the z-pin (green box in Figure 1).

These measurements allow for the calibration of the semi-analytical micro-mechanical bridging model, presented in (15). This is capable of predicting the continuous bridging forces exerted by the z-pin on the interlaminar crack faces, as functions of the delamination opening and sliding displacements. The modelling output at this length-scale is the amount of dissipated energy by an individual z-pin, $G_{m C}^{P}$, and its displacement at failure, $\delta_{m}^{f}$, as a function of mode-mixity (pink box in Figure 1).

These two outputs from the micro-scale model, $\left(G_{m C}^{P}, \delta_{m}^{f}\right)$, are fed into finite element models of macro-scale structural components. At this scale, it is possible to identify the bridging response and interaction of multiple z-pins. This interaction is represented by a smeared approach, using enhanced cohesive zone elements. This enhancement takes the form of an additional fracture energy, obtained from the micro-mechanical model, which accounts for the interlaminar toughening effect due to the presence of the z-pin. The exact formulation of this enhancement effect is defined in Section 5.

There are two main advantages in using this framework to model through-thickness reinforced composites: its simplicity of application at the macro-scale and its computational efficiency. The simplicity of application stems from the fact that no a priori knowledge of the exact position of the z-pin elements in the laminate is required, since these are not explicitly 
modelled. The model simply requires a standard cohesive element mesh at the interface prone to suffer delamination. Also, the implementation of the cohesive element model and integration of the bridging map information from the micro-mechanical model are achieved seamlessly without any specific intervention required by the user. The efficiency of the model derives from the very fast implementation into a cohesive law without the need to constantly search for the bridging tractions for each time increment of the finite element analysis, as in (26). Instead, a tri-linear cohesive law in closed form is implemented, accurately representing the most fundamental quantities of the bridging effect: the amount of energy dissipated and the total displacement at complete pull-out or bending failure of the z-pin.

\section{Meso-scale single z-pin testing}

Extensive experimental work has previously been performed to characterise the damage tolerance capability of through-thickness reinforced composite laminates. The response of laminates reinforced with a single z-pin under mode I (pull-out behaviour), mixedmode and mode II (shear behaviour) loading conditions have been analysed (27). The experimental data in terms of apparent fracture toughness against mode-mixity reveal that a transition region exists, where the behaviour of the z-pins shifts from complete pull-out (low mode-mixity) to z-pin fracture due to combined tension and bending (high mode-mixity).

\section{Micro-mechanical constitutive bridging model}

The micro-mechanical model, presented by Allegri et al. in (15), represents the bridging reinforcements as Euler-Bernoulli beams embedded in an elastic deformation undergoing small but finite rotations. It is assumed that the beams are orthogonal to the delamination crack plane. The beams are embedded in a Winkler type linear elastic foundation, as in (23). The z-pin fracture is taken into account by using a Weibull strength 
criterion. This allows for the transition from complete pull-out to z-pin fracture with increasing mode mixity $(\phi)$, which is associated with a decrease in apparent interlaminar fracture toughness $\left(W^{P}\right)$, to be captured. It is postulated that the pure mode II response can be entirely attributed to the fracture toughness associated with the tensile fibre failure of the bridging z-pin under bending loads. This can be demonstrated to be a valid assumption by observing the force-displacement curve of a pure mode II loading condition on an individual z-pin (Figure 2, taken from (27)). This curve is linear-elastic up to complete rupture of the zpin, giving evidence that the z-pin suffers sudden, brittle fracture without involving other energy dissipative mechanisms.

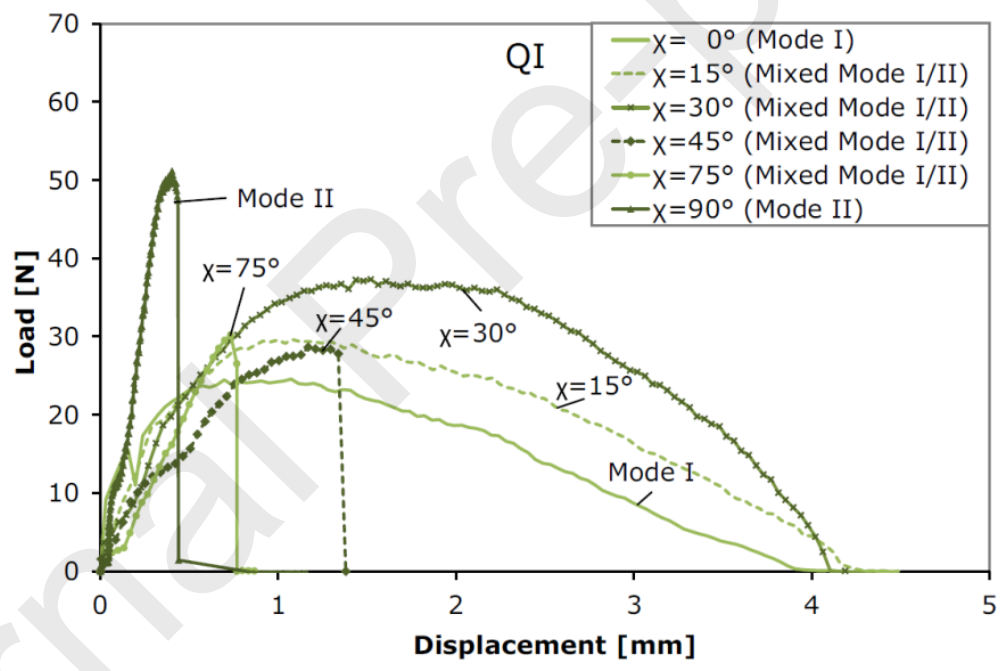

Figure 2. Representative Quasi-isotropic (QI) laminate load-displacement curves (from (27)).

The system of non-linear ordinary differential equations obtained with these considerations (see (15) for the full deduction of these equations and definition of all parameters) for the normalised transverse displacement $(y)$ and normalised axial force $(n)$ can be defined as: 


$$
\begin{gathered}
y^{I V}-n y^{I I}=\left\{\begin{array}{cc}
-4 \bar{\beta}^{4} y & , 0 \leq \xi \leq \alpha(1-d) \\
0 & \alpha(1-d)<\xi<\alpha
\end{array}\right. \\
-4 \bar{\beta}^{4}\left[y-\frac{\alpha \phi d}{\sqrt{1-\phi^{2}}}\left(\frac{L}{D}\right)\right] \quad \begin{array}{c}
, \alpha<\xi<1
\end{array} \\
n^{I}=\left\{\begin{array}{cc}
4 \bar{\beta}^{4}\left[\bar{\pi}^{-}(d)+\mu\left(\frac{D}{L}\right)|y|\right] & , 0 \leq \xi \leq \alpha(1-d) \\
0 & , \alpha(1-d)<\xi<\alpha \\
-4 \bar{\beta}^{4}\left[\bar{\pi}^{+}(d)+\mu\left(\frac{D}{L}\right)\left|y-\frac{\alpha \phi d}{\sqrt{1-\phi^{2}}}\left(\frac{L}{D}\right)\right|\right] & , \alpha<\xi<1
\end{array}\right.
\end{gathered}
$$

where:

$$
\begin{gathered}
\bar{\beta}=\frac{L}{\sqrt{2}} \sqrt[4]{\frac{\bar{k}_{x}}{E I}}, \quad \xi=\frac{z}{L}, \phi=\frac{U}{\sqrt{U^{2}+W^{2}}} \\
\bar{\pi}^{-}(d)=\frac{p_{0}+\left(p_{1}-p_{0}\right) e^{-\alpha f d L}}{\bar{k}_{x} L}, \bar{\pi}^{+}(d)=\frac{p_{1}}{\bar{k}_{x} L}
\end{gathered}
$$

In Equations (3), $U$ and $W$ respectively represent the sliding and opening displacements, $z$ is the abscissa in the $z$-pin axis, $\alpha$ is the insertion asymmetry (defined as the position of the delamination plane relative to z-pin length, e.g. 0.5 would be in the middle of the z-pin), $L$ is the z-pin insertion length, $D$ is the z-pin diameter, $E$ is the Young's modulus of the z-pin material in the axial direction, and $I$ is the z-pin cross-sectional second moment of area. Other input properties required to solve Equations (1)-(2) are the longitudinal strength of the z-pin, $X_{T}$; coefficient of Coulomb friction, $\mu$; foundation stiffness, $\bar{k}_{x}$; residual frictional forces per unit length, $p_{0}$ and $p_{1}$; enhancement coefficient for the residual frictional force, $f$; Weibull's exponent, $m$; reference volume for Weibull's failure criterion, $V_{0}$; and the fracture toughness for the tensile fibre failure of a z-pin, $G_{I C}^{f}$. The system of non-linear differential equations given in Equations (1)-(2) is numerically solved as a boundary value problem in $\operatorname{MATLAB}^{\circledR}$. The axial $(\bar{Z})$, transverse $(\bar{X})$ and bending $(\bar{M})$ bridging forces can then be expressed 
as a function of the normalised pull-out displacement $(d)$ and mode-mixity $(\phi)$ (the full deduction of these equations can be found in (15)):

$$
\begin{aligned}
& \bar{Z}(d, \phi)=\frac{E I}{L^{2}} n\left[\alpha\left(1-\frac{d}{2}\right)\right] \\
& \bar{X}(d, \phi)=\frac{E I D}{L^{2}}\left\{n\left[\alpha\left(1-\frac{d}{2}\right)\right] y^{I}\left[\alpha\left(1-\frac{d}{2}\right)\right]-y^{I I I}\left[\alpha\left(1-\frac{d}{2}\right)\right]\right\} \\
& \bar{M}(d, \phi)=\frac{E I D}{L^{2}} y^{I I}\left[\alpha\left(1-\frac{d}{2}\right)\right]
\end{aligned}
$$

The solution for the bridging forces is found by discretising the normalised pull-out displacement $d$ and mode-mixity $\phi$ ranges, so that for each value of $\phi, d$ increases incrementally. This numerical procedure is performed until the bridging z-pin satisfies the fibre failure criterion or complete pull-out is achieved.

For each mode mixity $(\phi)$, the amount of energy dissipated during the pull-out process is computed. If z-pin failure is predicted, then the energy associated with z-pin failure in tension is added, according with Equation 7,

$$
W^{P}=\alpha L \int_{0}^{d} \bar{Z} \mathrm{~d} d+\frac{\pi}{4} G_{I C}^{f} D^{2}
$$

Input parameters which relate to the intrinsic material properties of the z-pin or geometrical configuration are known a priori or can be assumed from values published in the open literature. However, parameters corresponding to the disturbed reinforced laminate are not known and need to be calibrated against meso-scale single z-pin testing. The five unknown calibrated input parameters are estimated by means of a parallelised genetic 
algorithm (GA). The first of these is the foundation stiffness provided to the bridging z-pin by the embedding laminate architecture, the frictional properties at the z-pin/resin pocket interface during pull-out and the strength and fracture of single z-pins. The foundation stiffness, $\bar{k}_{x}$, represents the influence of the laminate stacking sequence on the z-pin bridging behaviour. For the case of quasi-isotropic laminates, a linear elastic foundation can be demonstrated to be the most representative of the support provided by the fibres of the laminate for a lateral load (mode II) applied to the z-pin. The fibres will react to the lateral pressure exerted by the z-pin and, given their high strength and linear behaviour up to failure, will not allow for any non-linear behaviour of the z-pin bridging forces. The frictional properties characterise the frictional forces acting along the surface of the z-pin as pull-out occurs. These are the result of residual frictional forces due to thermal residual stresses acting along the interface of the z-pin, and Coulomb frictional forces. These properties influence the amount of energy dissipated during pull-out of the z-pin under mode I dominated loading conditions, and are a measure of the quality of the bonding between the z-pin and the laminate, as well as of the roughness of the interface between z-pin and laminate upon interfacial separation and subsequent relative sliding. There are three frictional properties represented by $p_{0}, p_{1}$, and $f$. The final property characterises the toughness of the z-pin. The mode I critical energy release rate, $G_{C C}^{f}$, will influence the amount of energy dissipated upon fracture of the z-pin under mode II dominated loading conditions. See (15) for further details on these properties. The genetic algorithm which calibrates these five parameters uses both dissipated energy versus mode-mixity data, as well as force-displacement curves for pure mode I and pure mode II loading conditions (as those in Figure 2), guaranteeing that the physical meaning of each parameter is taken into consideration. 
The micro-mechanical model is calibrated and validated against the aforementioned mixed-mode pull-out tests using a laminate with a single z-pin element. Using a quasiisotropic (QI) laminate configuration as a case study, the micro-mechanical bridging model is calibrated and validated by means of the apparent fracture toughness data obtained from mixed-mode pull-out testing of single carbon/BMI z-pins. As shown in Figure 3, the model is able to reproduce the correct trend of the apparent fracture toughness as function of the mode-mixity. A summary of the known, assumed and calibrated parameters are given in Table 1 , as per (15).

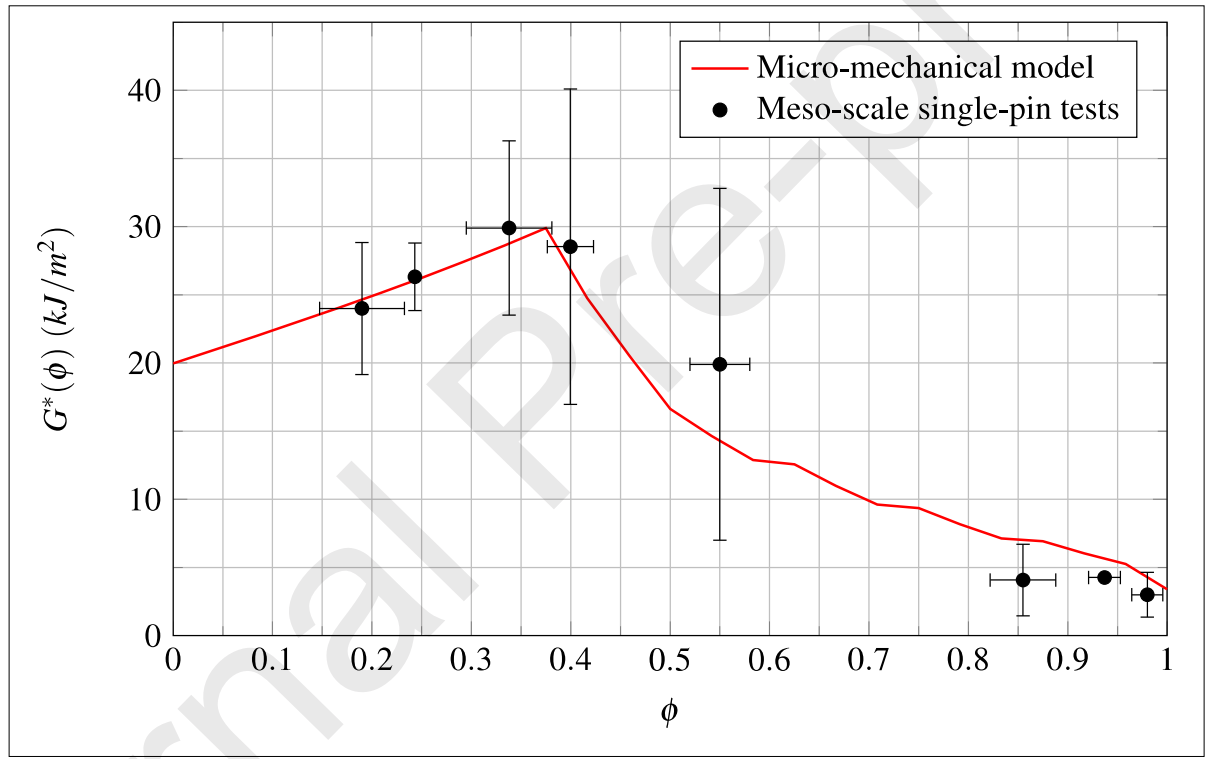

Figure 3. Apparent fracture toughness of single reinforced coupons normalised for a $2 \%$ areal density vs. mode-mixity $(15,27)$.

Table 1. Micro-mechanical model input parameters for T300/BMI z-pins.

\begin{tabular}{ccccc}
\hline \multicolumn{5}{c}{ Known z-pin insertion parameters } \\
\hline $\mathrm{D}(\mathrm{mm})$ & $\mathrm{L}(\mathrm{mm})$ & $\alpha(-)$ \\
0.28 & 8.0 & 0.5 & $\mathrm{~m}$ & $\mu(-)$ \\
\hline \multicolumn{5}{c}{ Assumed stiffness, strength and friction properties } \\
\hline $\mathrm{E}(\mathrm{GPa})$ & $\mathrm{X}_{\mathrm{T}}(\mathrm{MPa})$ & $\mathrm{V}_{0}\left(\mathrm{~mm}^{3}\right)$ & 27 & 0.7 \\
115 & 1860 & 2250 & 27 \\
\hline \multicolumn{5}{c}{ Calibrated model parameters } \\
\hline $\bar{k}_{x}\left(\mathrm{~N} / \mathrm{mm}^{2}\right)$ & $\mathrm{p}_{0}(\mathrm{~N} / \mathrm{mm})$ & $\mathrm{p}_{1}(\mathrm{~N} / \mathrm{mm})$ & $f(1 / \mathrm{mm})$ & $G_{f C}^{f}(\mathrm{~N} / \mathrm{mm})$ \\
165 & 10.5 & 0.375 & 1.5 & 170 \\
\hline
\end{tabular}


As mentioned above, a Matlab ${ }^{\circledR}$ script has been written to solve the system of nonlinear ordinary differential equations. The output of the micro-scale model is a single text file containing tabulated records of the dissipated energy calculated according to Equation (7) and the total displacement at which complete pull-out or z-pin rupture occurs. These are defined according with Equation (8), where $\delta_{I}$ and $\delta_{I I}$ represent the pull-out and sliding displacements, respectively. These results are output for each mode-mixity ratio.

$$
\phi=\frac{\delta_{I I}}{\sqrt{\delta_{I I}^{2}+\delta_{I}^{2}}}
$$

The output text file has format compatible with the commercial finite element software LS-DYNA ${ }^{\circledR}$, where the remaining parts of the simulation framework are run.

\section{Macro-scale finite element analysis}

The implementation of the micro-mechanical constitutive bridging law into a finite element framework is achieved via means of a user-defined interface constitutive law formulated for cohesive elements in the explicit finite element solver, LS-DYNA ${ }^{\circledR}$ (28). An explicit scheme is here considered to avoid severe convergence issues that can be encountered during material softening.

The bridging length for inserted z-pins will depend on the mode-mixity applied. Here, the term 'bridging length' refers to the length of the delamination plane that is still being bridged by active z-pins, although the delamination crack has already propagated through. Figure 4 provides a schematic of a mode I dominant load case, where, as the delamination propagates, z-pins are pulled out from one half of the laminate becoming inactive (in red), i.e. 
no longer contribute towards the bridging effect, while the remaining z-pins, even if partially pulled-out, are still active and contributing towards bridging (in green).

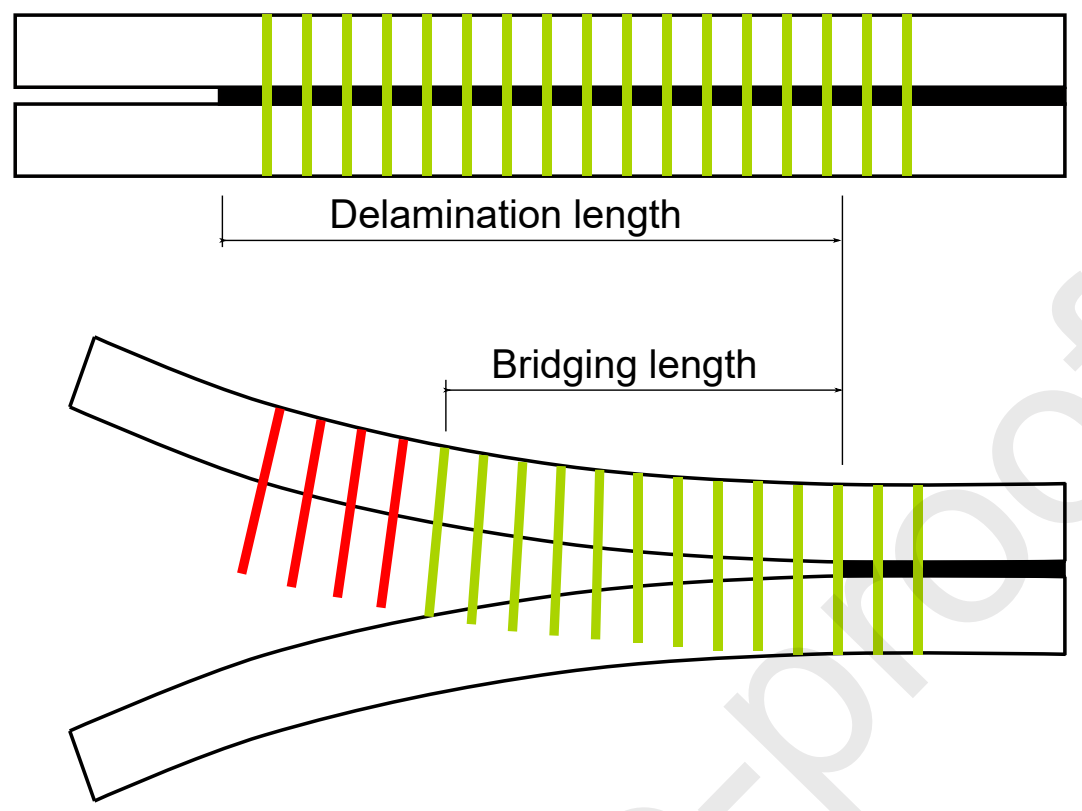

Figure 4. Schematic of a mode I dominant load case, showing the concept of bridging length, and active z-pins (in green), and inactive z-pins (in red).

A mode II dominant loading scenario typically leads to all the z-pins in the laminate to be actively bridging the two halves of the laminate after a crack has propagated through the matrix; hence, there is no scale effect in this case. On the other hand, under a mode I dominant loading case, as shown in Figure 4, the bridging length will depend on the thickness of the laminate, i.e. the z-pins will tend to be completely pulled-out from one side of the laminate (normally the shortest side) and the active z-pins will be those still in the process of being pulled-out and providing bridging between the two halves of the laminate, while all other z-pins will not be active; consequently, the thicker the laminate (and longer the z-pin), the greater the bridging length will be as well as the dissipated energy. Given this relation between z-pin length and bridging length, one can conclude that these two lengths are of a similar order of magnitude (albeit not equal). 
The user-defined interface constitutive law is written in a Fortran 90 subroutine. At each time step, the LS-DYNA ${ }^{\circledR}$ solver computes the displacements and opening rates and passes these arguments to the user-defined cohesive subroutine. The resulting tractions at the integration points at the end of the time step are computed based on the defined constitutive law, stored history variables and material constants and are passed back to the main part of the finite element code for use in the next time step.

\subsection{Energy dissipated by matrix}

The matrix material is assumed to follow the classic Cohesive Zone Model (CZM), as described in $(29,30)$. The underlying principles of the CZM are that the inelastic state of the fracture process zone can be represented by a surface of interface elements. The CZM relates the tractions $\sigma$ to displacement jumps $\delta$ at the crack interface. Damage initiation is governed by the interfacial strength, which is followed by a linear softening in which the energy dissipated during the crack opening is controlled via the intrinsic toughness $G_{C}$ (i.e. the area under the traction-separation curve). Tractions are reduced to zero when the displacement jump is equal to, or greater than, the displacement at failure $\delta_{f}$ and a new crack surface is formed.

The three dimensional map of the mixed-mode formulation is illustrated in Figure 5, where the mode I and mode II traction-displacements are represented on the $0-\sigma_{n}-\delta_{n}$ and 0 $\sigma_{s}-\delta_{s}$ planes, respectively. The pure mode I and mode II bi-linear responses are shown in 0$\sigma_{I}^{O M}-\delta_{I}^{f}$ and $0-\sigma_{I I}^{O M}-\delta_{I I}^{f}$ planes, respectively. According to a Cartesian coordinate system $X_{i}$, $i=1,2,3$ the normal opening displacement is defined as $\delta_{I}=\delta_{3}$, and the separation in the resultant shear direction is $\delta_{I I}=\sqrt{\delta_{1}^{2}+\delta_{2}^{2}}$. The mixed-mode response is inferred from any 
point on the $0-\sigma-\delta_{m}$ plane, in which the total mixed-mode relative displacement is defined as $\delta_{m}=\sqrt{\delta_{I}^{2}+\delta_{I I}^{2}}$.

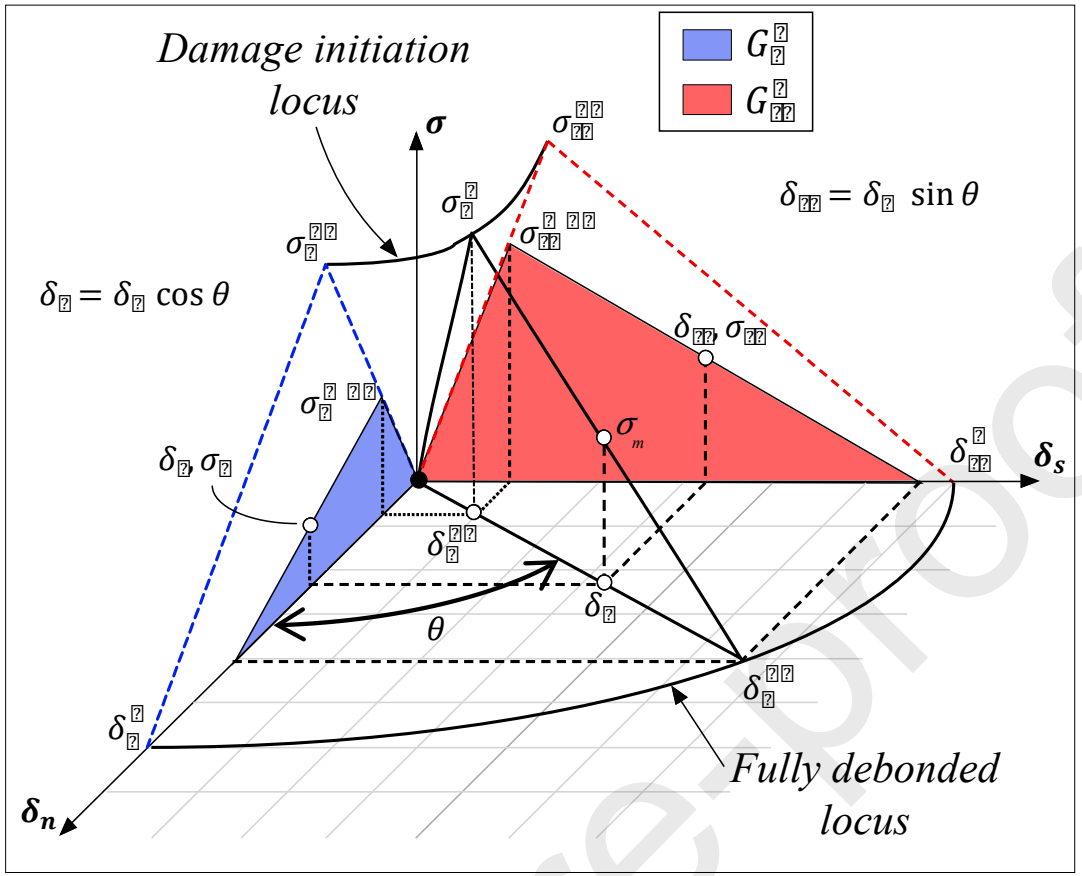

Figure 5. Bi-linear mixed-mode softening law.

Following (30), under the presence of through-thickness compression $\left(\sigma_{I}<0\right)$, then the shear strength and the energy dissipation ratio in mode II for the epoxy matrix are enhanced as follows:

$$
\begin{gathered}
\sigma_{I I}^{O M, E}=\sigma_{I I}^{O M}-\eta \sigma_{I} \\
G_{I I C}^{M, E}=G_{I I C}^{M}\left(\frac{\sigma_{I I}^{o M, E}}{\sigma_{I I}^{o M}}\right)^{2}
\end{gathered}
$$

\subsubsection{Damage initiation criterion}

The mixed-mode damage initiation displacement $\delta_{m}^{\mathrm{o} M}$ (onset of softening) follows a quadratic damage initiation criterion under a multi-axial traction state and is given by: 


$$
\left(\frac{\left\langle\sigma_{I}^{\max }\right\rangle}{\sigma_{I}^{o M}}\right)^{2}+\left(\frac{\sigma_{I I}^{\max }}{\sigma_{I I}^{o M, E}}\right)^{2}=1
$$

where $\sigma_{I}^{\max }$ and $\sigma_{I I}^{\max }$ are the maximum traction levels in the current loading direction for mode I and mode II, respectively.

$$
\begin{aligned}
& \sigma_{I}^{\max }=k_{I}^{M} \delta_{m}^{o M} \cos \theta \\
& \sigma_{I I}^{\max }=k_{I I}^{M} \delta_{m}^{o M} \sin \theta
\end{aligned}
$$

In Equations (12) and (13), $k_{I}^{M}$ and $k_{I I}^{M}$ are the initial normal and shear stiffness of the interface, and $\cos \theta$ and $\sin \theta$ are the direction cosines for the current loading direction. In the displacement jump space, the criterion becomes:

$$
\delta_{m}^{o M}=\frac{1}{\sqrt{\left(\frac{k_{I}^{M} \cos \theta}{\sigma_{I}^{o M}}\right)^{2}+\left(\frac{k_{I I}^{M} \sin \theta}{\sigma_{I I}^{o M}}\right)^{2}}}
$$

\subsubsection{Damage propagation criterion (Option 1 - Power law)}

The well-known power-law criterion is implemented to predict delamination propagation under mixed-mode loading and it is expressed as:

$$
\left(\frac{G_{I}^{M}}{G_{I C}^{M}}\right)^{\alpha}+\left(\frac{G_{I I}^{M}}{G_{I I C}^{M}}\right)^{\alpha}=1
$$

where $\alpha \in(1.0-2.0)$ is an empirical parameter derived from mixed-mode experimental results. $G_{I C}^{M}$ and $G_{I I C}^{M}$ are the critical energy release rates for pure mode I and II, respectively. Thus, the propagation criterion in the displacement space is: 


$$
\delta_{m}^{f M}=\left(\left(\frac{\sigma_{I}^{\max } \cos \theta}{2 G_{I C}^{M}}\right)^{\alpha}+\left(\frac{\sigma_{I I}^{\max } \sin \theta}{2 G_{I I C}^{M}}\right)^{\alpha}\right)^{-\frac{1}{\alpha}}
$$

\subsubsection{Initial damage surface \& propagation criterion - (Option 2 - B-K law)}

A mixed-mode failure criterion proposed by Benzeggagh and Kenane (31), the $B-K$ law, is additionally implemented into the CZM. The B-K law has been shown to give more accurate predictions of mixed-mode fracture toughness in polymer-based composites (32) and it reads

$$
G_{m C}^{M}=G_{I C}^{M}+\left(G_{I I C}^{M}-G_{I C}^{M}\right)\left(\frac{k_{I I}^{M} \sin ^{2} \theta}{k_{I}^{M} \cos ^{2} \theta+k_{I I}^{M} \sin ^{2} \theta}\right)^{\eta_{B K}}
$$

where $\eta_{B K}$ is an empirical parameter obtained from MMB tests at different mode ratios (32). Consequently, the "full debond" locus, which describes the total mixed-mode displacement to failure $\delta_{m}^{f M}$, can be defined as:

$$
\delta_{m}^{f M}=\frac{2 G_{m C}^{M}}{\sigma_{I}^{\max } \cos \theta+\sigma_{I I}^{\max } \sin \theta}
$$

\subsubsection{Damage variable definition and energy dissipated by matrix}

Independently of the criterion chosen, a simple mixed-mode damage parameter $d_{m}^{M}$ is defined to track the extent of damage accumulation at the interface:

$$
d_{m}^{M}=\frac{\delta_{m}-\delta_{m}^{o M}}{\delta_{m}^{f M}-\delta_{m}^{o M}}
$$

The energy dissipated by delamination propagation in the matrix material can thus be calculated following:

$$
G_{I}^{M}=\frac{\sigma_{I}^{\max } \delta_{m}^{f M} \cos \theta}{2}
$$




$$
G_{I I}^{M}=\frac{\sigma_{I I}^{\max } \delta_{m}^{f M} \sin \theta}{2}
$$

\subsection{Energy dissipated by z-pins}

After calculating the contribution from the matrix material to the dissipated energy for the current mode-mixity, the algorithm proceeds with a search for the dissipated energy by an individual z-pin. The bridging map library from the micro-mechanical model is treated as a vertical lookup table from which the dissipated energy and the displacement at failure are calculated for the current mode-mixity and geometrical parameters (z-pin length and asymmetry). If the current value of mode-mixity is not available from the lookup table, then an interpolation is performed between the two closest bridging map entries.

The modelling strategy that has been implemented does not require accounting for the actual locations of individual z-pins, nor their individual contributions to the energy dissipation. Instead, a cohesive formulation approach is considered here, where the energy dissipated by an individual z-pin $\left(W^{P}\right)$ is smeared across the cohesive area of the interface elements, as a function of the z-pin areal-density $\left(Z_{A D}\right)$ of the reinforced regions and the diameter of a z-pin $(D)$. This leads to the following expression:

$$
G_{m C}^{S}=W^{P} * Z_{A D} \frac{4}{\pi D^{2}}
$$

where $G_{m C}^{S}$ represents the apparent fracture toughness smeared across the interface region.

\subsection{Total dissipated energy}

While a delamination propagates through a reinforced area, the crack front passes through the matrix material and it impinges individual z-pin elements. As already mentioned 
above, the modelling framework proposed here is based on a smeared representation of the bridging actions exerted by z-pins via a fracture energy equivalence.

The rationale for such a choice is that delamination propagation is an intrinsically energy-driven process whereby interlaminar crack growth causes a dissipation of mechanical energy. Here we consider the quotas of mechanical energy dissipated by both materials matrix and z-pin - in a combined fashion. Given that the dissipated energies are not recoverable, and they are associated to independent mechanisms, these can be simply summed. The total dissipated energy associated with the progressive fracture of an interface with z-pin is therefore given by:

$$
G_{m C}^{T}=G_{m C}^{S}+G_{m C}^{M}
$$

This method will from now on be referred as Energy Equivalent Bridging Map (EEBM).

The name stems from the fact that, although the actual bridging forces from the bridging maps calculated by the micro-scale analytical model are no longer used themselves (as in (26)), the dissipated energy and the displacement at failure computed from those bridging maps are. An equivalent stress state can be defined and directly related to that of the real bridging forces. This guarantees identical amount of energy dissipation during crack propagation and the correct failure mode and displacement for the z-pin. The approach does not lead to any loss of applicability since the bridging map is calculated for the complete mixmode space, allowing for the EEBM method to be used under any loading condition applied to the laminate. Naturally, if the material system of either laminate or z-pin are modified, then the full framework needs to be calibrated again, via meso-scale experimental 
characterisation of the bridging behaviour of individual z-pins and the micro-mechanical constitutive bridging model for generation of the bridging maps.

From this point onwards, an inverse process with respect to a traditional CZM formulation is followed. In a traditional CZM model, the pure mode I and pure mode II loading conditions are known a priori, and the combined mixed-mode behaviour is then determined. Using the EEBM approach, it is the combined mixed-mode behaviour that is initially known, and from it the limit conditions corresponding to pure tension and pure shear stress at the interface are determined. Figure 6 represents the concept schematically.

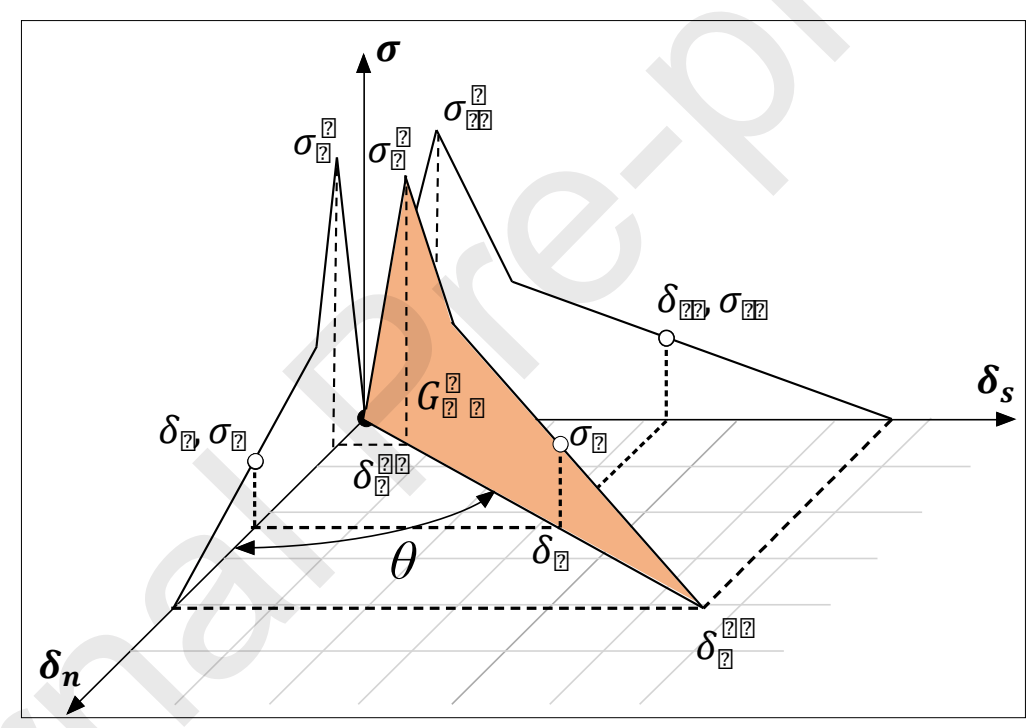

Figure 6. Energy equivalent bridging map.

The area in orange in Figure 6 becomes completely defined by three parameters. The dissipated energy, $G_{m C}^{T}$, and the displacement at failure, $\delta_{m}^{f P}$, are known from the micromechanical model described in Section 4. A cohesive stiffness, $k_{c}$, can be defined by the user, in agreement with published literature (32). The cohesive behaviour is modelled using a trilinear formulation which accounts for both the failure of the epoxy matrix and the bridging effect brought by the z-pin. Figure 7 illustrates the concept. The red shaded area corresponds 
to the energy dissipated by the fracture of the epoxy material, $G_{m C}^{M}$, while the green shaded area corresponds to the energy dissipated by the bridging effect ascribed to the z-pin, $G_{m C}^{S}$. For clarity of the representation, the areas are not to scale; typically, the energy dissipated by the matrix is much lower than that dissipated by the z-pin. A tri-linear cohesive formulation has been used in the past by Gutkin et al. (33) to capture the artificial augmentation of toughness brought by individual fibre bridging in crack propagation of CT coupons.

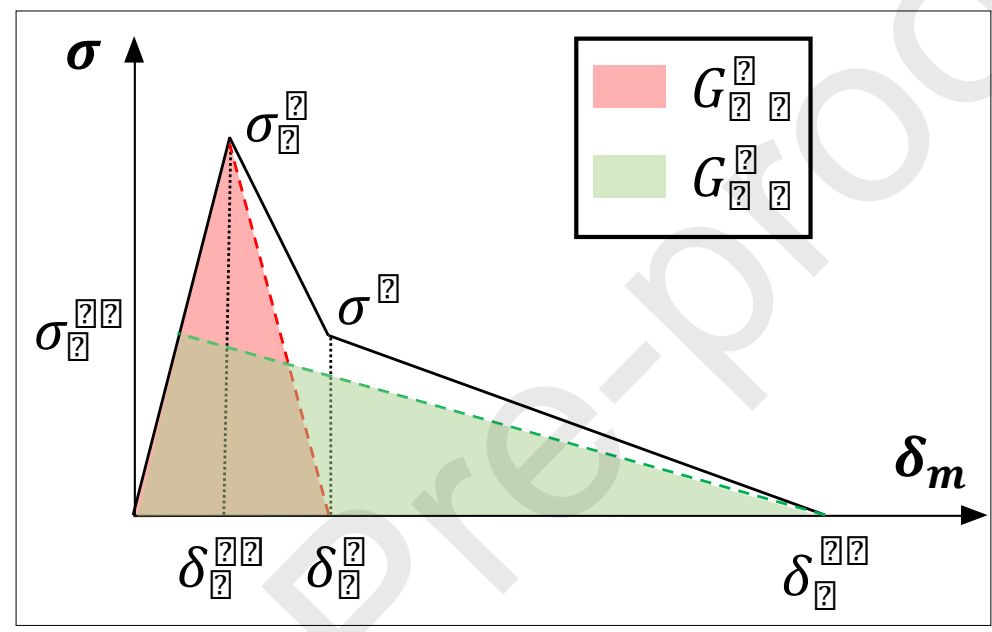

Figure 7. Illustration of tri-linear cohesive law in the mixed-mode plane.

The area under the tri-linear cohesive law (thick black line in Figure 7) will correspond to the sum of the dissipated energies, $G_{m c}^{T}$. The maximum stress, $\sigma_{m}^{o}$, corresponds to the strength of the epoxy; while the maximum on the green curve, $\sigma_{m}^{o P}$, can be computed from the two parameters from the micro-scale model as:

$$
\sigma_{m}^{o P}=\frac{2 G_{m C}^{S}}{\delta_{m}^{f P}}
$$

The point at which the slope of the damage evolution changes represented by $\left(\delta_{m}^{I}, \sigma^{I}\right)$ is defined by the displacement at failure of the epoxy resin computed from Equation (16) or 
Equation (18), depending on the damage propagation criterion selected for the matrix. The corresponding stress is given by:

$$
\sigma^{I}=\frac{\sigma_{m}^{o P} \delta_{m}^{f P}}{\delta_{m}^{f P}-\delta_{m}^{o M}}
$$

Equation 25 is derived from enforcing the area under the tri-linear curve equal to the sum of the dissipated energies from both matrix and z-pin. The stresses in the progressive damage case can be calculated from the following:

$$
\sigma_{m}=\left\{\begin{array}{cc}
\sigma_{m}^{o M}-d_{S}^{M}\left(\sigma_{m}^{o M}-\sigma^{I}\right), & \delta_{m}<\delta_{m}^{I} \\
\sigma^{I}\left(1-d_{S}^{P}\right) & \quad \delta_{m} \geq \delta_{m}^{I}
\end{array}\right.
$$

where $d_{S}^{M}$ and $d_{S}^{P}$ represent the damage parameters associated with each of the propagation regions of the tri-linear cohesive law before and after complete failure of the matrix, at $\delta_{m}^{I}$. $\delta_{m}$ corresponds to the current displacement in the mixed-mode plane $\theta$, while $\delta_{m}^{o M}$ represents the displacement at failure initiation in the mixed-mode plane $\theta$. Hence:

$$
\begin{gathered}
d_{S}^{M}=\frac{\delta_{m}-\delta_{m}^{o M}}{\delta_{m}^{I}-\delta_{m}^{o M}} \\
d_{S}^{P}=\frac{\delta_{m}-\delta_{m}^{I}}{\delta_{m}^{f P}-\delta_{m}^{I}}
\end{gathered}
$$

In the elastic regime, the traction and shear stresses can be calculated from:

$$
\sigma_{I}=\delta_{m} E_{m} \cos \theta
$$




$$
\sigma_{I I}=\delta_{m} E_{m} \sin \theta
$$

Finally, in the case of unloading with existing damage, the stress can be calculated from:

$$
\sigma_{m}=\left\{\begin{array}{cc}
{\left[\sigma_{m}^{o M}-d_{S}^{M}\left(\sigma_{m}^{o M}-\sigma^{I}\right)\right] \frac{\delta_{m}}{\delta_{m}^{o M}+d_{S}^{M}\left(\delta_{m}^{I}-\delta_{m}^{o M}\right)},} & \delta_{m}<\delta_{m}^{I} \\
\sigma^{I}\left(1-d_{S}^{P}\right) \frac{\delta_{m}}{\delta_{m}^{f M}+d_{S}^{P}\left(\delta_{m}^{f P}-\delta_{m}^{I}\right)} & , \delta_{m} \geq \delta_{m}^{I}
\end{array}\right.
$$

The traction and shear stress components can be determined from:

$$
\begin{gathered}
\sigma_{I}=\sigma_{m} \cos \theta \\
\sigma_{I I}=\sigma_{m} \sin \theta
\end{gathered}
$$

If the damage parameter $d_{S}^{P}$ exceeds the value 1 , then the integration point is considered failed and no longer able to withstand any loading. The traction and shear stresses are therefore set equal to zero. Throughout the analysis, a loading/unloading condition applies. This guarantees a monotonically decreasing variation of stresses in case of load removal, without further propagation or recovery from damage until the loading status before unloading is resumed. This condition is satisfied if the damage variable at the current time increment is greater than at any previous time increment. Only if this condition is satisfied there will be damage progression. If the condition is not satisfied, the integration point is unloaded back to a stress-free state. 


\section{Model verification}

\subsection{Experimental set-up}

A series of experimental tests aimed at characterising the behaviour of throughthickness reinforced coupons at different mode-mixity ratios has been previously performed (26). The following is a summary of the test set-up used.

Double cantilever beam (DCB), end-loaded-split (ELS) and mixed-mode bending (MMB) tests were conducted. For the DCB tests, the ASTM-D5528 standard (34) was followed to generate a mode I delamination. The ASTM-D6671 standard (35) for mixed-mode bending (MMB) testing of UD FRP composites was followed to experimentally investigate mixed mode I/mode II cases. Finally, the mode II ELS test follows the guidelines provided by the European Structural Integrity Society in the standard ESIS-TC4 01-04-02 (36). Figure 8 schematically shows the three test configurations. It is worth mentioning that the MMB test requires the computation of the lever distance $c$, which is a function of the mode-mixity at which the test will be performed. This parameter can be computed according to Equation (34).

$$
c=\frac{12 \beta^{2}+3 \alpha+8 \beta \sqrt{3 \alpha}}{36 \beta^{2}-3 \alpha} L
$$

where $L$ represents the distance between hinge and top support $(L=65)$ and the parameters $\alpha$ and $\beta$ are given by Equations (35) and (36).

$$
\alpha=\frac{1-\frac{G_{I I}}{G_{T}}}{G_{I I} / G_{T}}
$$




$$
\begin{gathered}
\beta=\frac{a_{0}+\chi h}{a_{0}+0.42 \chi} \\
\chi=\sqrt{\frac{E_{11}}{11 G_{13}}\left\{3-2\left(\frac{\Gamma}{1+\Gamma}\right)^{2}\right\}} \\
\Gamma=1.18 \frac{\sqrt{E_{11} E_{22}}}{G_{13}}
\end{gathered}
$$

For the MMB tests, the distance $c$ was set to $101.1 \mathrm{~mm}, 57.5 \mathrm{~mm}$, and $41.0 \mathrm{~mm}$, corresponding to nominal mode II percentages of $25 \%, 47 \%$, and $69 \%$, respectively. 64 plies of carbon-epoxy IM7/8552 were laid-up with the stacking sequence $\left[(0 /-45 / 90 / 45)_{4 s}\right]_{S}$. The z-pin rods were made of pultruded T300/BMI. The specimens had an initial crack $a_{o}$ formed by inserting a thin PTFE film in the mid-plane of the specimen before curing. The through-thickness reinforced region covered $22.75 \mathrm{~mm}$ in length and spanned the entire width of the specimen. Having an unreinforced region ahead of the initial starter crack tip gives a clear indication of the bridging effect of the z-pin once a delamination has initiated and propagated during testing. These tests allow for the validation of the modelling framework described in Section 2 with a configuration in which the predominant damage mechanisms is large-scale bridging, without any other interaction with intra- or trans-laminar failure.

\subsection{Numerical models}

All models presented here are run using type 19 cohesive element formulation implemented in LS-DYNA ${ }^{\circledR}$ R7.1.3, with the proposed EEBM user material model. Based on previous modelling experience and to reduce the computational runtime, a simplified 'unit strip' model is introduced, with plane strain boundary conditions along the edges. The cohesive element formulation effectively 'smears' the periodic z-pin arrangement across the 
elemental area, hence the individual representation of the z-pins is not required. The unreinforced region is modelled with the standard Cohesive Zone Model described in (30). Eight-node selectively reduced solid elements are used to model the composite laminate beams. This element formulation accurately captures the laminate rotations. Schematics of the modelling setup for the DCB, ELS and MMB test cases are shown in Figure 9. Material properties used for the composite laminate are given in Table 2. The material properties used for the cohesive elements (both reinforced and unreinforced regions) are given in Table 3. The areal density of the reinforced region is $Z_{A D}=0.02$ and the z-pin diameter is $D=0.28 \mathrm{~mm}$. 


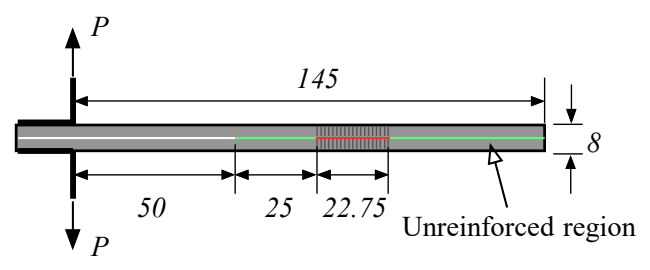

Mixed-Mode Bending (MMB)

Mixed-Mode I/II

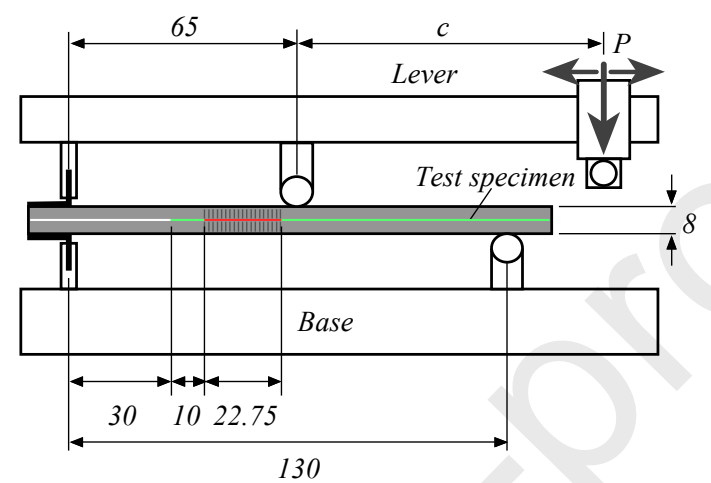

End-Loaded Split (ELS)

Mode II

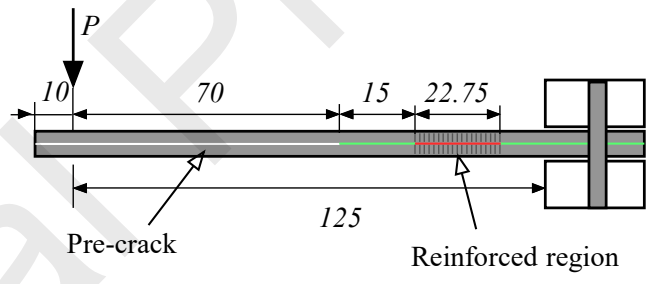

Figure 8. Delamination tests configuration and specimens' geometries (26).

The in-plane cohesive element size is determined such that there are 4-5 elements within the fracture process zone. The cohesive element length used is $0.25 \mathrm{~mm}$ along the crack propagation direction for all simulations. This element size is imposed by the low fracture toughness of the unreinforced interface regions (37). All models have $1.0 \mathrm{~mm}$ width and only one element per width was introduced, since the crack propagation is orthogonal to this direction. Three elements are used in the thickness direction on each of the specimen 
arms. To account for the width effect, plane strain boundary conditions were applied to all models. The loading velocity in all solutions is approximately $1.0 \mathrm{~mm} / \mathrm{s}$ (defined initially by a ramp rate followed by a constant velocity), which produced satisfactory results with negligible dynamic effects. For the mode II ELS tests, a frictionless contact condition has been defined between the two halves of the laminate.

Table 2. Material properties for QI IM7/8552 carbon-fibre-reinforced composite.

\begin{tabular}{ccccccc}
\hline $\begin{array}{c}E_{11}=E_{22} \\
(\mathrm{GPa})\end{array}$ & $E_{33}$ & $G_{12}$ & $G_{13}=G_{23}$ & $v_{12}$ & $v_{31}$ & $v_{32}$ \\
$(\mathrm{GPa})$ & $(\mathrm{GPa})$ & $(\mathrm{GPa})$ & $(-)$ & $(-)$ & $(-)$ \\
\hline 61.60 & 13.61 & 23.37 & 4.55 & 0.32 & 0.07 & 0.1 \\
\hline
\end{tabular}

Table 3. Material properties for cohesive elements.

\begin{tabular}{cccccccc}
\hline $\begin{array}{c}\sigma_{I}^{O M} \\
(\mathrm{MPa})\end{array}$ & $\begin{array}{c}\sigma_{I I}^{O M} \\
(\mathrm{MPa})\end{array}$ & $\begin{array}{c}k_{I}^{M}=k_{I I}^{M} \\
\left(\mathrm{~N} / \mathrm{mm}^{3}\right)\end{array}$ & $\begin{array}{c}G_{I C}^{M} \\
(\mathrm{~N} / \mathrm{mm})\end{array}$ & $\begin{array}{c}G_{I I C}^{M} \\
(\mathrm{~N} / \mathrm{mm})\end{array}$ & $\begin{array}{c}k_{c} \\
\left(\mathrm{~N} / \mathrm{mm}^{3}\right)\end{array}$ & $\begin{array}{c}\eta_{B K} \\
(-)\end{array}$ & $\begin{array}{c}\eta \\
(-)\end{array}$ \\
\hline 60.0 & 90.0 & $10^{5}$ & 0.21 & 0.78 & $10^{5}$ & 1.94 & 0.7 \\
\hline
\end{tabular}

Double Cantilever Beam (DCB) Mode I

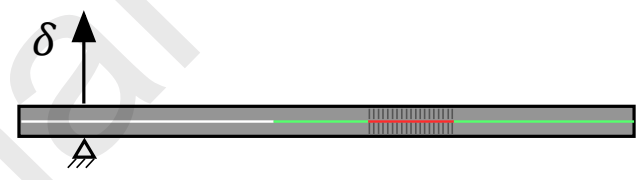

Mixed-Mode Bending (MMB) Mixed-Mode I/II

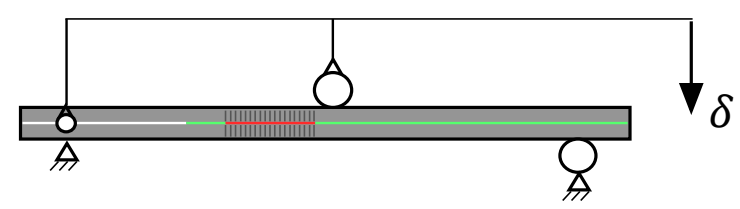

End-Loaded Split (ELS)

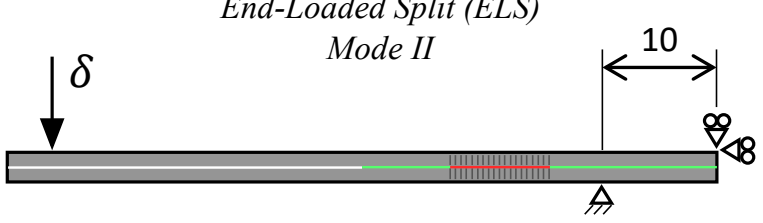

Figure 9. Simplified unit-strip FE models. 


\subsection{Numerical results}

\subsubsection{Double Cantilever Beam (DCB)}

A comparison between the test results from the experimental test programme and the numerical predictions from the macro-scale model is presented in Figure 10 for the pure mode I case. Results from running the same model with the classical CZM formulation (as if the specimen did not have any z-pins inserted), and results obtained from using the built-in MAT_138 material model of LS-DYNA for cohesive elements, are also presented for reference. Results from the proposed Energy Equivalent Bridging Map (EEBM) formulation are presented with a solid blue line. As it can be seen, an excellent agreement is found between the experimental and numerical results. An initial linear elastic response is observed after which the crack-tip propagates through the initial unreinforced region with a consequent small load drop. The crack-tip then reaches the first row of z-pins, which begin to exert traction bridging forces. Z-pins partially suppress further crack opening displacements. This phenomenon is characterised by a gradual increase in the global force response.

In the experimental test, the arms of the laminate are under severe bending conditions, which lead to localised sub-laminate buckling close to the outer plies of the laminate. Not only failure from buckling, but also smaller delaminations can be found close to the surface (see Figure 11). These localised sources of damage in the specimens cause small load drops towards the end of the test. The finite element models for validation of the cohesive formulation here do not account for these phenomena, therefore the load curve from the numerical simulation is not capable of capturing them. This explains why the numerical curve seems to diverge from the experimental results beyond a crosshead displacement of $35.0 \mathrm{~mm}$. 


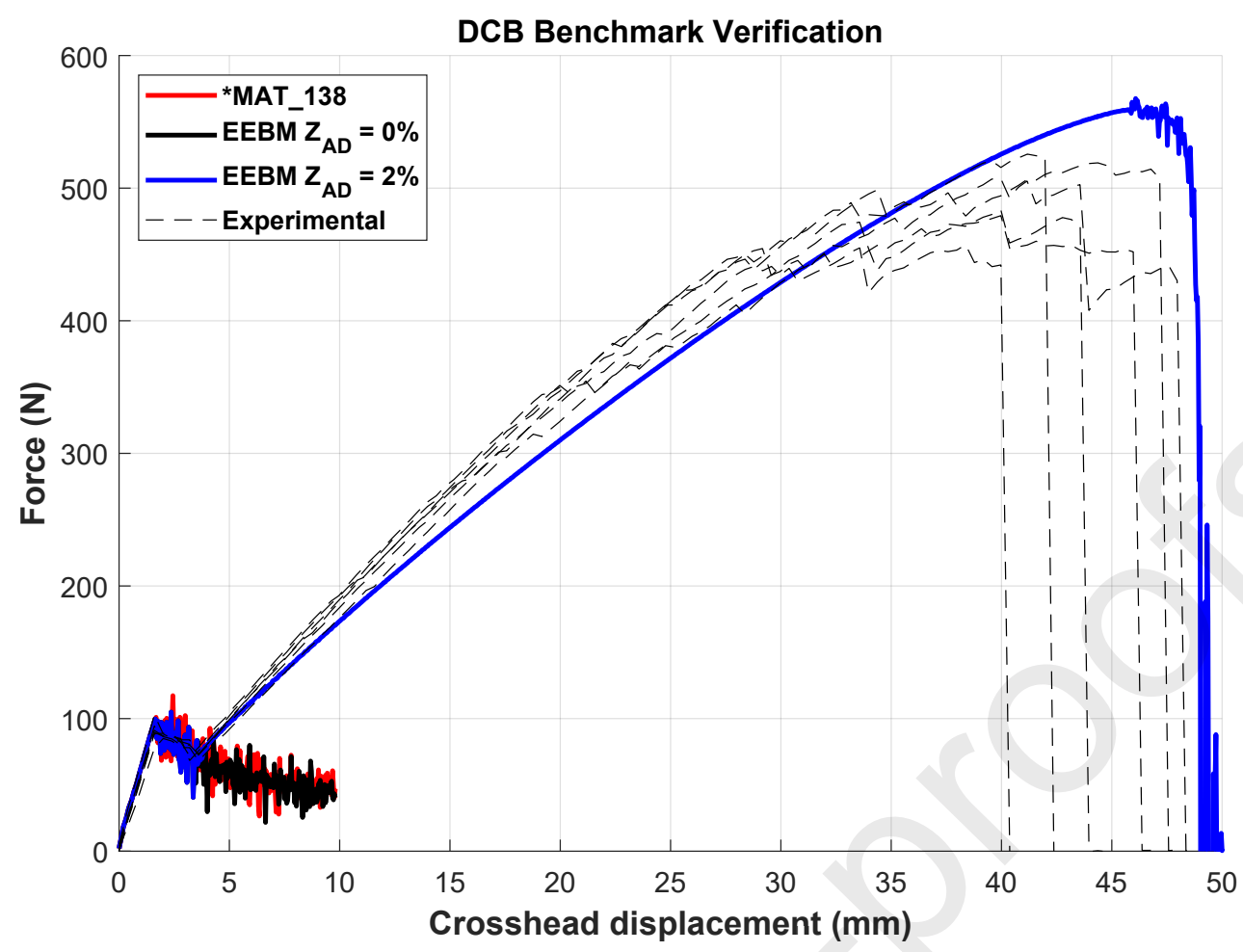

Figure 10. Comparison between DCB (Mode I) experimental results and numerical prediction.

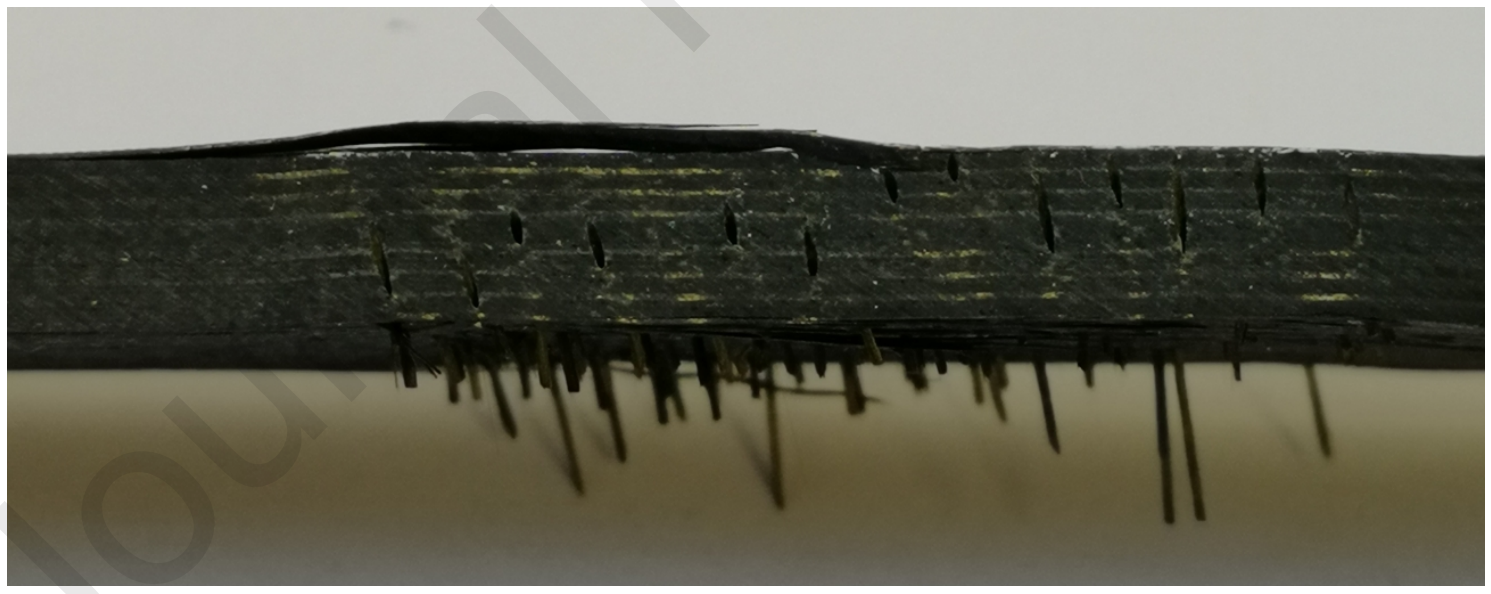

Figure 11. Upper half laminate of DCB test specimen after test showing buckling and delamination in the outer layers.

\subsubsection{Mixed-Mode Bending (MMB)}

As mentioned above, three different values of mode-mixity have been experimentally characterised. The first value, i.e. $25 \%$ mode II, is within the range of mode-mixities leading to a complete pull-out of z-pins, with only few z-pins suffering complete failure. Figure 12 
shows the comparison between the experimental and the numerical results for an effective mode-mixity of $25 \%$. An excellent agreement between numerical predictions and test results can be observed. Very similarly to what had been observed on the DCB case, a considerable displacement of the crosshead at failure is reached in the tests and the simulations. This is due to the fact that, at this level of mode-mixity, most of the z-pins will still suffer a complete pull-out

The test arrest criterion for the MMB coupons has been defined when the crack-tip reaches $60.0 \mathrm{~mm}$. From this point onwards, there was a tendency for the laminate to suffer other sources of damage, such as buckling of the outer plies due to bending, and a secondary delamination appeared at the loading blocks, as shown in Figure 14. This occurred at a crosshead displacement of approximately $19.2 \mathrm{~mm}$ for $\mathrm{MMB} 25 \%$. The numerical model captures the behaviour of the bridging action exerted by the z-pins very well. After an initial linear elastic stage, the crack-tip propagates through the initial unpinned region, until it is slowed down by the through-thickness reinforced area. The z-pins resist interlaminar crack growth in a very effective fashion.

The second mode-mixity value was $47 \%$ mode II. In this condition, both complete pullout and shear failure are expected to occur in the z-pins, leading to a reduced amount of dissipated energy during the bridging process. Figure 13 shows the comparison between the experimental results and the numerical predictions. Just like the MMB 25\%, there was a tendency for the laminate to suffer other failure modes (see Figure 14). In the experimental results, a crosshead displacement of $11.2 \mathrm{~mm}$ corresponds to the crack-tip reaching $60.0 \mathrm{~mm}$ length. As it can be appreciated in Figure 13, an excellent agreement between experimental and numerical results is observed also for the $47 \%$ mode-mixity. 
Figure 15 shows the comparison between experimental results and numerical predictions for the mode-mixity value of $69 \%$. The test arrest criterion is again when the cracktip reaches $60.0 \mathrm{~mm}$. At this mode-mixity, there is a much lower probability for the z-pins to be pulled out, while shear failure tends to occur quickly after the start of the bridging process. Consequently, the amount of energy dissipated in the bridging process is smaller than in the previous cases. When the crack-tip reaches $60.0 \mathrm{~mm}$, the crosshead displacement is only $7.5 \mathrm{~mm}$. Before the crack tip reaches this point, the experimental and numerical curves tend to diverge slightly. The inflection in the numerical curve stems from the loss of stiffness caused by all cohesive elements entering in the damage propagation region of the tri-linear cohesive formulation.

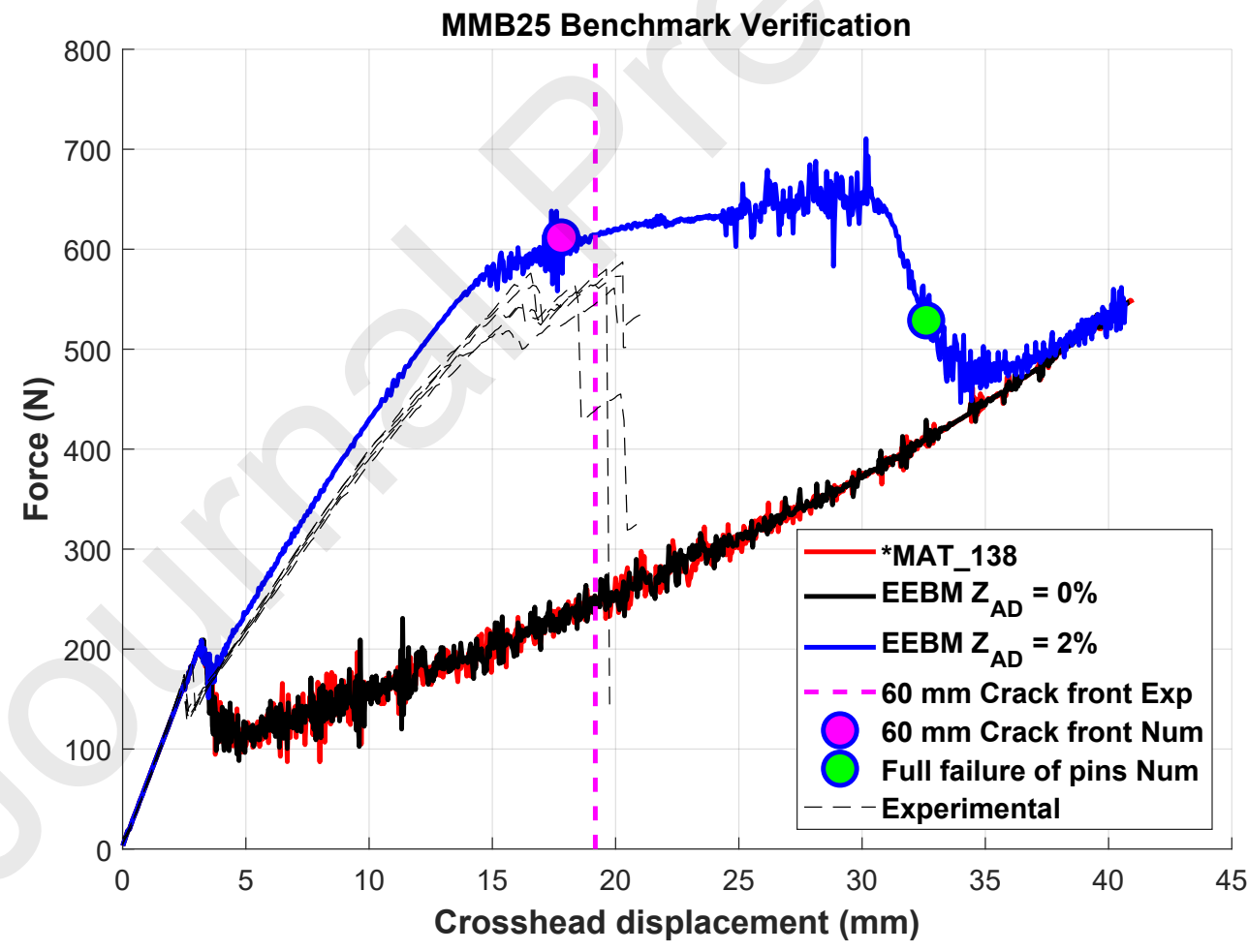

Figure 12. Comparison between MMB 25\% experimental results and numerical prediction. 


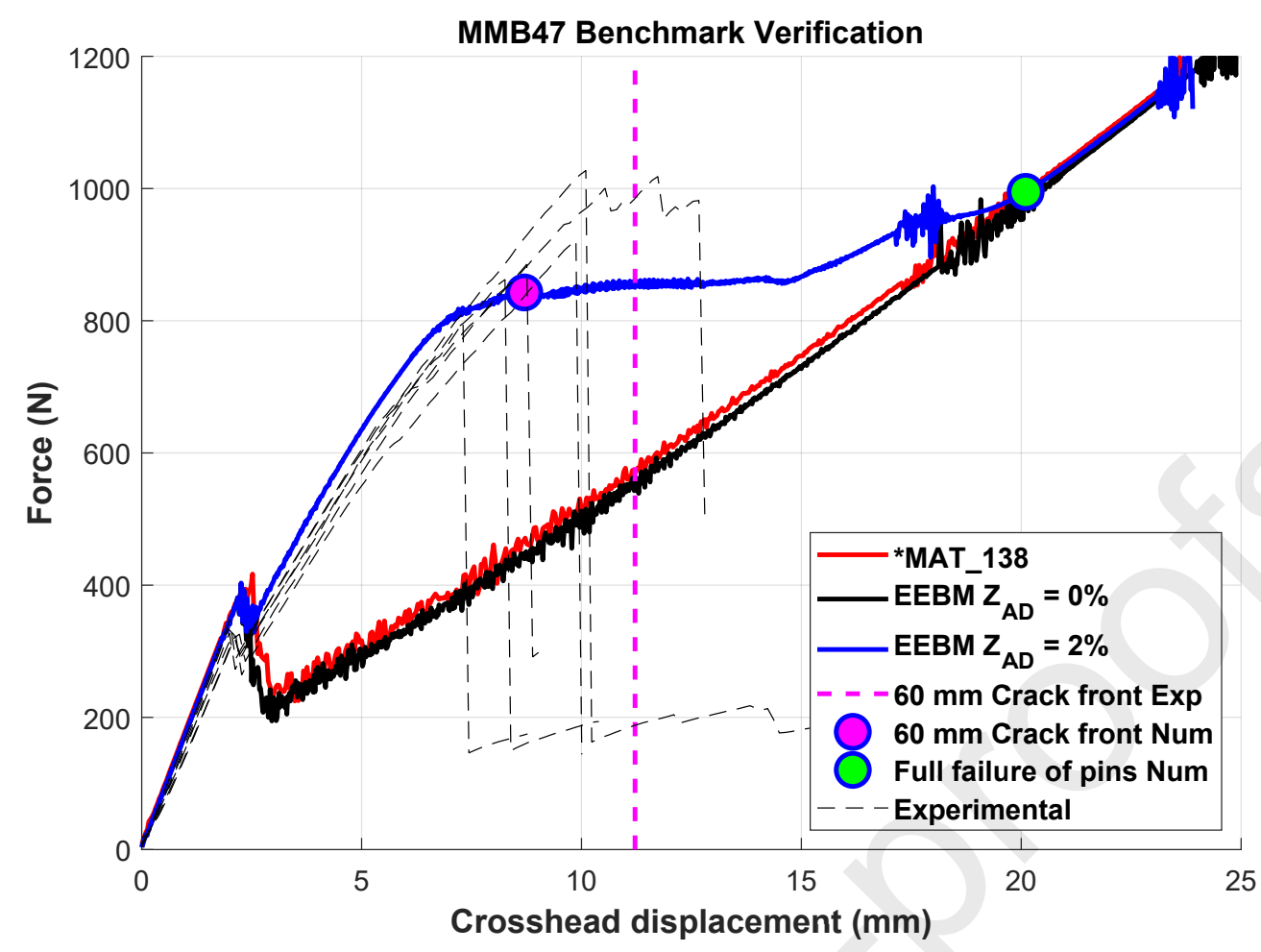

Figure 13. Comparison between MMB 47\% experimental results and numerical prediction.

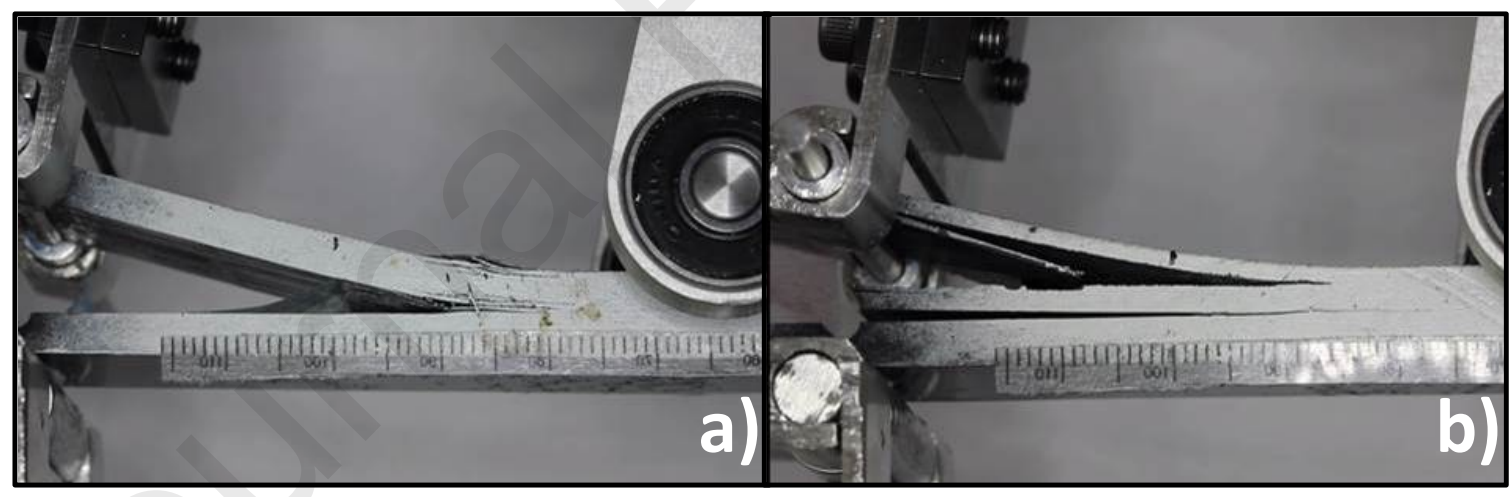

Figure 14. a) Local buckling of the outer plies and b) secondary delamination on MMB $47 \%$ test specimens. 


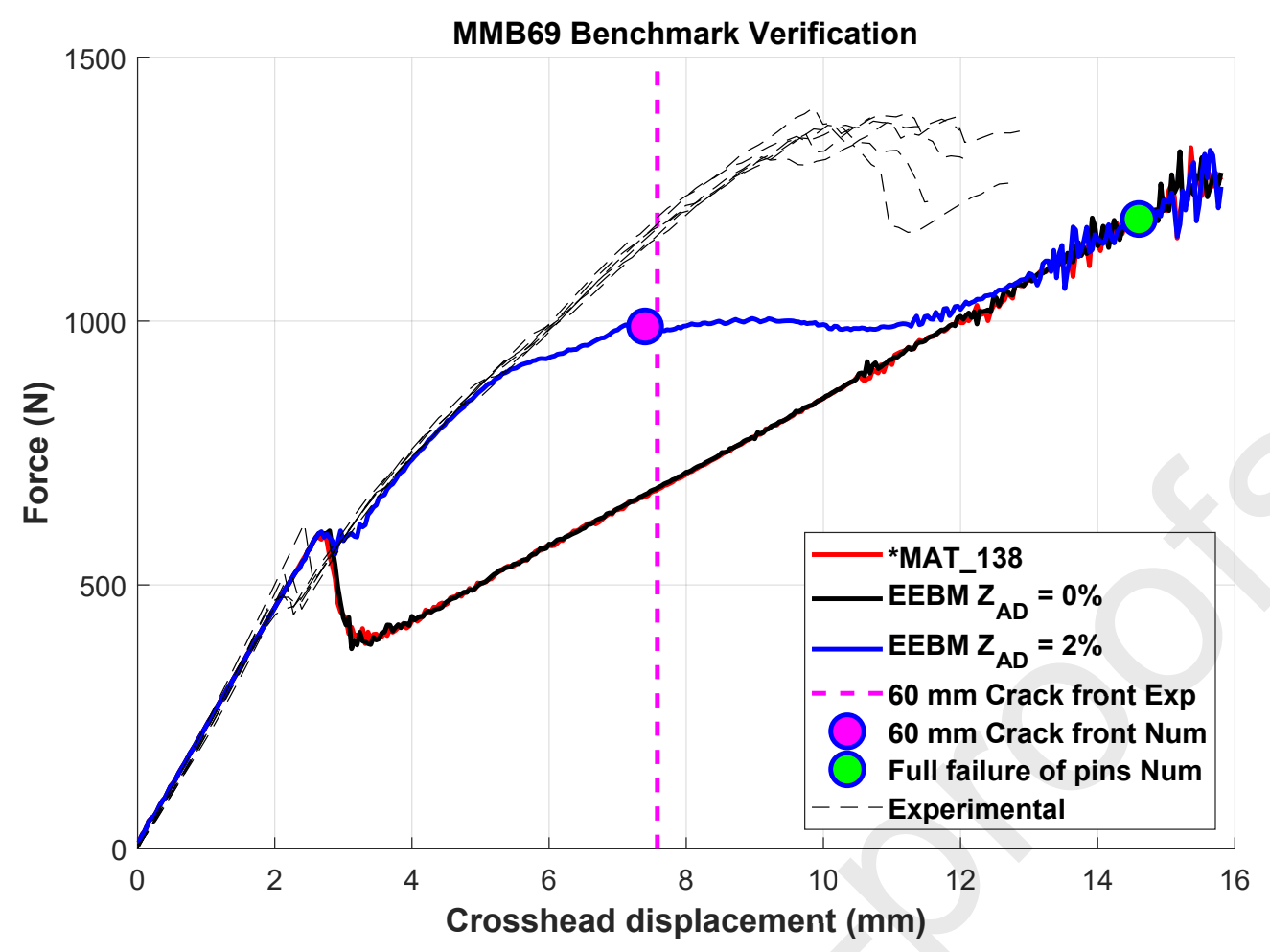

Figure 15. Comparison between MMB 69\% experimental results and numerical prediction.

The load-displacement curve seen on Figure 15 presents an initial linear elastic behaviour, followed by failure of the unreinforced region and then delamination propagation into the z-pin reinforced area. Analogously to the previous test cases, the crack is arrested by the first array of z-pins, which will continue to bridge the two halves of the laminate until shear failure of the z-pins occurs. The Energy Equivalent Bridging Map formulation can capture the bridging effort very well in this test case as well.

\subsubsection{End-Loaded Split (ELS)}

The final benchmark test is a pure mode II loading condition. Figure 16 presents a comparison between experimental results and numerical predictions for the ELS test case. The arrest criterion for this case is when the crack-tip reaches the clamped end of the specimen. In complete analogy with the previous test cases, after an initial linear elastic 
behaviour, the crack-tip propagates through the unpinned region until it reaches the first line of z-pins and it is arrested. This corresponds to the first line drop in the load-displacement curve, which is followed by a progressive reloading.

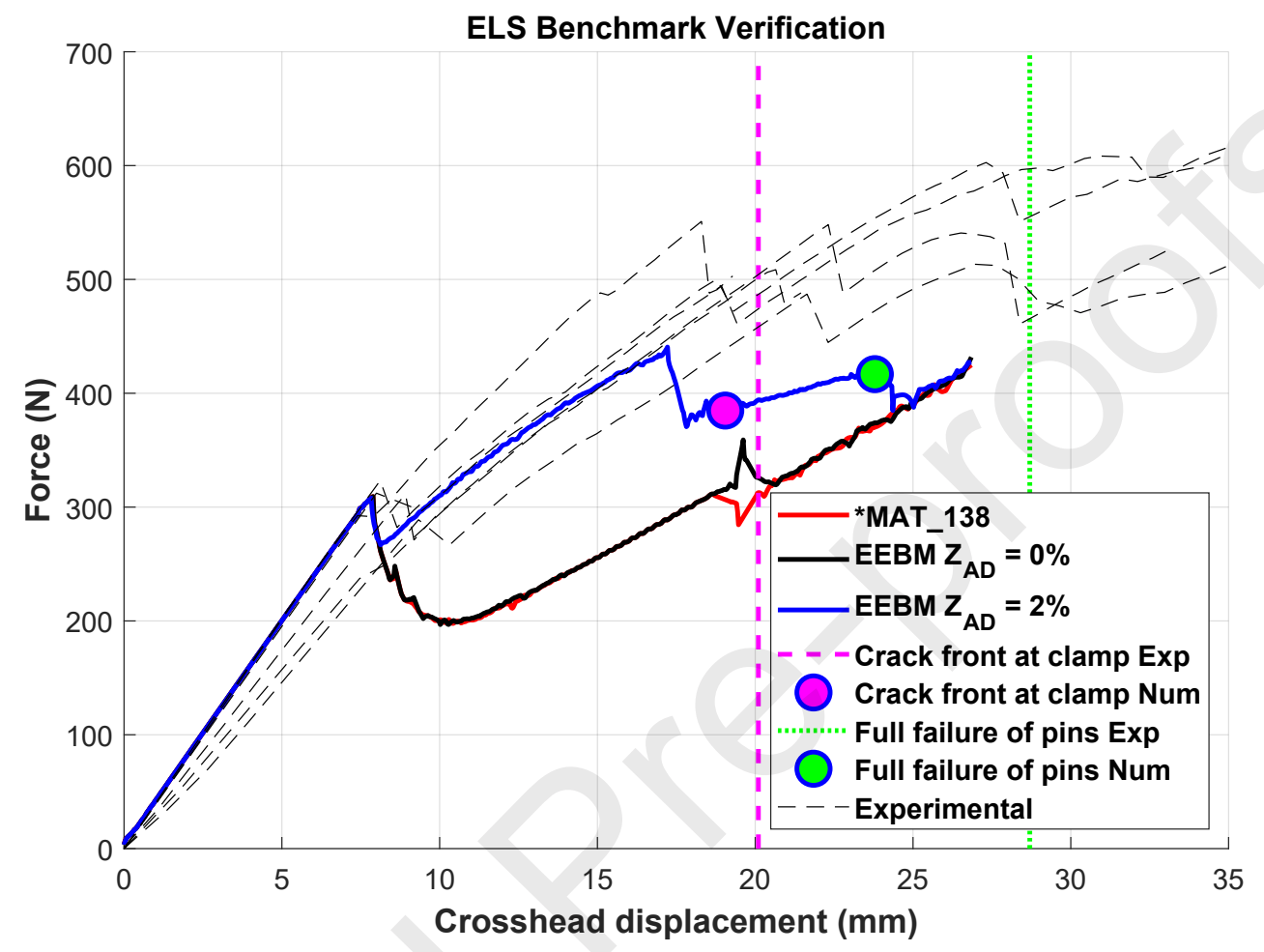

Figure 16. Comparison between ELS (Mode II) experimental results and numerical prediction.

The delamination continues to propagate along the specimen, and it will eventually emerge from the reinforced region. This occurs without failure of the z-pins. Once the cracktip reaches the second unreinforced region of the specimen, it quickly grows and reaches the clamped end (vertical dashed line in Figure 16 at crosshead displacement of $21.0 \mathrm{~mm}$ ). In the numerical results, when the crack-tip reaches the clamped end, some numerical noise occurs. Both experimental results and numerical predictions agree well at this stage. 


\section{Conclusions}

A comprehensive numerical framework has been presented, whereby a user-defined cohesive element formulation has been developed to simulate the large-scale bridging response of through-thickness-reinforced composite specimens. This is achieved by successfully integrating the predictions from a micro-mechanical constitutive bridging model into the cohesive element formulation. The micro-mechanical model describes the mixedmode loading behaviour of through-thickness reinforcements as Euler-Bernoulli beams embedded within a Winkler elastic foundation. It is assumed that the z-pin is inserted orthogonally to the delamination plane. This constitutive model is valid for a general mixedmode regime and was calibrated using meso-scale test coupons of single z-pins in a QI composite laminate. The output of this model is the amount of energy dissipated and the displacement at failure or complete pull-out of the z-pin for a range of mixed-mode displacement values.

Special user-defined cohesive elements were developed. These can describe both the resin-rich interface layer and the large-scale bridging mechanism due to the presence of z-pins. At each time increment, the mixed-mode displacement at the integration point is used to identify the amount of energy being dissipated by the z-pin and the predicted total displacement at failure for that specific mode-mixity. This information is used to reverse-build a tri-linear cohesive constitutive law, which correctly represents both the amount of energy dissipated by the bridging action and the total displacement at failure of the z-pin. This process allows calculation of the traction and shear components of the bridging forces acting along the cohesive interface. The procedure has been denoted here as an Energy Equivalent Bridging Map (EEBM) formulation. 
The multi-scale framework has been validated against a comprehensive set of experimental data for different loading conditions and mixed-mode ratios. The general applicability of the presented framework allows for the numerical analysis of complex structures with through-thickness reinforcements without the need for special modelling techniques. A standard finite element model with cohesive elements along the interface is sufficient. The framework has also been implemented in an efficient way, with a direct integration of the output of the micro-mechanical bridging model into the macro-scale finite element analysis.

Future developments will extend the capability of this framework to model simultaneous multiple delamination planes, as well as the influence of environmental effects such as temperature and moisture on the bridging capability of a z-pin.

\section{Acknowledgements}

The authors wish to acknowledge the support of Rolls-Royce plc through the Composites University Technology Centre (UTC) at the University of Bristol, UK. The financial support from the UK Aerospace Technology Institute through the CTI Composite Fan Technology (CTIFAN) project (ref. no. 113085) is also acknowledged.

\section{References}

1. Wisnom MR. The role of delamination in failure of fibre-reinforced composites. Philosophical Transactions of the Royal Society A: Mathematical, Physical and Engineering Sciences. 2012;370(1965):1850-70.

2. Mouritz A. Review of Z-pinned composite laminates. Composites Part A: Applied Science and Manufacturing. 2007;38(12):2383-97.

3. Partridge IK, Cartié DDR. Delamination resistant laminates by Z-Fiber ${ }^{\circledR}$ pinning: Part I manufacture and fracture performance. Composites Part A: Applied Science and Manufacturing. 2005;36(1):55-64. 
4. Cartié DDR, Cox BN, Fleck NA. Mechanisms of crack bridging by composite and metallic rods. Composites Part A: Applied Science and Manufacturing. 2004;35(11):1325-36.

5. Pegorin F. An experimental investigation of multi-functional z-pinned carbon-epoxy composites. 2016.

6. Wang S, Zhang Y, Wu G. Interlaminar Shear Properties of Z-Pinned Carbon Fiber Reinforced Aluminum Matrix Composites by Short-Beam Shear Test. Materials (Basel). 2018;11(10).

7. M'Membe B, Yasaee M, Hallett SR, Partridge IK. Effective use of metallic Z-pins for composites' through-thickness reinforcement. Composites Science and Technology. 2019;175:77-84.

8. Virakthi A, Kwon S, Lee SW, Robeson ME. Delamination resistance of composite laminated structures reinforced with angled, threaded, and anchored Z-pins. Journal of Composite Materials. 2019;53(11):1507-19.

9. Cui H, Yasaee M, Kalwak G, Pellegrino A, Partridge IK, Hallett SR, et al. Bridging mechanisms of through-thickness reinforcement in dynamic mode I\&ll delamination. Composites Part A: Applied Science and Manufacturing. 2017;99:198-207.

10. Hoffmann J, Scharr G. Compression properties of composite laminates reinforced with rectangular z-pins. Composites Science and Technology. 2018;167:463-9.

11. Hoffmann J, Scharr G. Mode I delamination fatigue resistance of unidirectional and quasi-isotropic composite laminates reinforced with rectangular z-pins. Composites Part A: Applied Science and Manufacturing. 2018;115:228-35.

12. Toral Vazquez J, Castanié B, Barrau J-J, Swiergiel N. Multi-level analysis of low-cost Zpinned composite joints: Part 2: Joint behaviour. Composites Part A: Applied Science and Manufacturing. 2011;42(12):2082-92.

13. Francesconi L, Aymerich F. Effect of Z-pinning on the impact resistance of composite laminates with different layups. Composites Part A: Applied Science and Manufacturing. 2018;114:136-48.

14. Gornet L, ljaz H, Cartié D. Inelastic Interface Damage Modeling with Friction Effects: Application to Z-Pinning Reinforcement in Carbon Fibre Epoxy Matrix Laminates. Journal of Composite Materials. 2010;44(17):2067-81.

15. Allegri G, Yasaee M, Partridge IK, Hallett SR. A novel model of delamination bridging via Z-pins in composite laminates. International Journal of Solids and Structures. 2014;51(1920):3314-32.

16. Zhang B, Allegri G, Yasaee M, Hallett SR. Micro-mechanical finite element analysis of Z-pins under mixed-mode loading. Composites Part A: Applied Science and Manufacturing. 2015;78:424-35.

17. Nguyen ATT, Pichitdej N, Brandt M, Feih S, Orifici AC. Failure modelling and characterisation for pin-reinforced metal-composite joints. Composite Structures. 2018;188:185-96.

18. Li M, Chen P. A new FE model for predicting the bridging micromechanisms of a Z-pin. Composite Structures. 2019;223:110957.

19. Baber F, Ranatunga V, Guven I. Peridynamic modeling of low-velocity impact damage in laminated composites reinforced with z-pins. Journal of Composite Materials. 2018;52(25):3491-508.

20. Ravindran AR, Ladani RB, Wang $\mathrm{CH}$, Mouritz AP. Synergistic mode II delamination toughening of composites using multi-scale carbon-based reinforcements. Composites Part A: Applied Science and Manufacturing. 2019;117:103-15. 
21. Blacklock M, Joosten MW, Pingkarawat K, Mouritz AP. Prediction of mode I delamination resistance of z-pinned laminates using the embedded finite element technique. Composites Part A: Applied Science and Manufacturing. 2016;91:283-91.

22. Freels J. Modeling Fracture in Z-Pinned Composite Co-Cured Laminates Using Smeared Properties and Cohesive Elements in DYNA3D. 2006:105.

23. Bianchi $F$, Zhang X. Predicting mode-II delamination suppression in z-pinned laminates. Composites Science and Technology. 2012;72(8):924-32.

24. Sam Huang H, Waas AM. Quasi-static mode II fracture tests and simulations of Zpinned woven composites. Engineering Fracture Mechanics. 2014;126:155-65.

25. Cui H, Li Y, Koussios S, Beukers A. Mixed mode cohesive law for Z-pinned composite analyses. Computational Materials Science. 2013;75:60-8.

26. Mohamed G, Allegri G, Yasaee M, Hallett SR. Cohesive element formulation for z-pin delamination bridging in fibre reinforced laminates. International Journal of Solids and Structures. 2018;132-133:232-44.

27. Yasaee M, Lander JK, Allegri G, Hallett SR. Experimental characterisation of mixed mode traction-displacement relationships for a single carbon composite Z-pin. Composites Science and Technology. 2014;94:123-31.

28. LS-DYNA Keyword User's Manual Volume II Material Models R7.1. LSTC; 2014.

29. Jiang W-G, Hallett SR, Green BG, Wisnom MR. A concise interface constitutive law for analysis of delamination and splitting in composite materials and its application to scaled notched tensile specimens. International Journal for Numerical Methods in Engineering. 2007;69(9):1982-95.

30. Li X, Hallett SR, Wisnom MR. Predicting the effect of through-thickness compressive stress on delamination using interface elements. Composites Part A: Applied Science and Manufacturing. 2008;39(2):218-30.

31. Benzeggagh $\mathrm{ML}$, Kenane $\mathrm{M}$. Measurement of mixed-mode delamination fracture toughness of unidirectional glass/epoxy composites with mixed-mode bending apparatus. Composites Science and Technology. 1996;56(4):439-49.

32. Camanho PP, Davila CG. Mixed-Mode Decohesion Finite Elements for the Simulation of Delamination in Composite Materials. Technical Report. NASA Langley Research Center; Hampton, VA United States; 2002 Jun 01, 2002. Report No.: NASA/TM-2002-211737, L-18194, NAS 1.15:211737.

33. Gutkin R, Laffan ML, Pinho ST, Robinson P, Curtis PT. Modelling the R-curve effect and its specimen-dependence. International Journal of Solids and Structures. 2011;48(11):176777.

34. ASTM-D5528-01. Standard Test Method for Mode I Interlaminar Fracture Toughness of Unidirectional Fiber-Reinforced Polymer Matrix Composites. ASTM International; 2007.

35. ASTM-D6671-06. Standard Test Method for Mixed Mode I-Mode II Interlaminar Fracture Toughness of Unidirectional Fibre Reinforced Polymer Matrix Composites. 2006.

36. ESIS-TC4-01-04-02. Fibre-reinforced plastic composites - Determination of apparent Mode II interlaminar fracture toughness, Gllc, for unidirectionally reinforced materials. European Structural and Integrity Society - Technical Committee 4; 2002.

37. Turon A, Dávila CG, Camanho PP, Costa J. An engineering solution for mesh size effects in the simulation of delamination using cohesive zone models. Engineering Fracture Mechanics. 2007;74(10):1665-82. 